\title{
Geology of Ceres' North Pole quadrangle with Dawn FC imaging data
}

\author{
Ottaviano Ruesch ${ }^{\mathrm{a}, *}$, Lucy A. McFadden ${ }^{\mathrm{b}}$, David A. Williams ${ }^{\mathrm{c}}$, Kynan H.G. Hughson ${ }^{\mathrm{d}}$, \\ Jan Hendrik Pasckert ${ }^{\mathrm{e}}$, Jennifer Scully ${ }^{\mathrm{f}}$, Thomas Kneissl ${ }^{\mathrm{g}}$, Thomas Roatsch ${ }^{\mathrm{h}}$, Andrea Naß ${ }^{\mathrm{h}}$, \\ Frank Preusker ${ }^{\mathrm{h}}$, Nico Schmedemann ${ }^{\mathrm{g}}$, Simone Marchi ${ }^{\mathrm{i}}$, Harald Hiesinger ${ }^{\mathrm{e}}$, Ralf Jaumann ${ }^{\mathrm{h}}$, \\ Andreas Nathues ${ }^{\mathrm{j}}$, Carol A. Raymond ${ }^{\mathrm{f}}$, Christopher T. Russell ${ }^{\mathrm{d}}$
}

a Planetary Systems Laboratory - code 693, NASA Goddard Space Flight Center/Universities Space Research Association (USRA), 8800 Greenbelt Road, Greenbelt, MD 20771, USA

${ }^{\mathrm{b}}$ NASA GSFC, Greenbelt, MD 20771, USA

'School of Earth E' Space Exploration, ASU, Tempe, AZ 85004, USA

dUCLA, Los Angeles, CA 90095, USA

e Institut fuer Planetologie, WWU, Muenster, Germany

f JPL, Caltech, Pasadena, CA, USA

${ }^{\mathrm{g}}$ Freie Universitaet Berlin, Berlin, Germany

${ }^{\text {h }}$ DLR, 12489 Berlin, Germany

i SwRI, Boulder, CO, USA

${ }^{\mathrm{j}}$ MPI for Solar System Research, Göttingen, Germany

\section{A R T I C L E I N F O}

\section{Article history:}

Received 22 September 2016

Revised 14 September 2017

Accepted 26 September 2017

Available online 3 October 2017

Keywords:

Asteroid Ceres

Geological processes

Impact processes

\begin{abstract}
A B S T R A C T
The Dawn Framing Camera repeatedly imaged Ceres' North Pole quadrangle (Ac- 1 Asari, latitudes $>66^{\circ} \mathrm{N}$ ) at a resolution of $\sim 35 \mathrm{~m} /$ pixel through a panchromatic filter, enabling the derivation of a digital terrain model (DTM) and an ortho-rectified mosaic. Using this dataset, a photo-geologic map and stratigraphy, complemented with absolute model ages of impact craters, were produced. We identified the following key surface features: an ancient $4.5 \mathrm{~km}$ high isolated dome with a non-impact origin; recent lobate materials on crater interiors possibly formed as high-speed flows of collapsed rim material; and recent bright areas in permanently shadowed regions (PSRs), which we interpret as ice accumulation mostly by infall of exogenic material. Crater morphologies and dimensions do not differ from those in other quadrangles, suggesting the widespread influence of a rheologically weak target during the crater formation process. There is a paucity of lobate materials associated with impact cratering, in contrast to previous identifications with lower spatial resolution imagery.
\end{abstract}

(c) 2017 Elsevier Inc. All rights reserved.

\section{Introduction}

With a diameter of $940 \mathrm{~km}$ and a density of $2160 \mathrm{~kg} \mathrm{~m}^{-3}$ Ceres is the largest and most massive intact body in the Main Asteroid Belt. The successful orbital operations of the Dawn spacecraft around Ceres (Russell et al., 2016) enabled the Framing Camera (FC) instrument (Sierks et al., 2011) to collect comprehensive optical imagery of the surface (Nathues et al., 2015). The derived global geological characterization allows for reconsideration and expansion of knowledge of Ceres' surface and interior properties and its evolution. Impact craters dominate Ceres' surface geology as they are globally widespread and can occur at a high spatial density (Hiesinger et al., 2016). The relation between crater

\footnotetext{
* Corresponding author.

E-mail address: ruesch@protonmail.com (O. Ruesch).
}

shapes (i.e., diameter and depth) and morphologies (e.g., central peak, central pit and terraces) indicate that Ceres' outer shell behaves with a weak rheology at short timescales (during impact crater formation), reminiscent of the crust of icy satellites (e.g., Ganymede) (Hiesinger et al., 2016). However, the majority of impact craters have kept their original shape and therefore did not undergo viscous relaxation. This implies that on a longer timescale the outer shell behaves with a relatively stronger rheology, modeled as a shallow subsurface composed of a mixture of rock-salts with less than 30-40\% by volume of water ice (Bland et al., 2016). Subsurface ice abundance and surface temperature have been suggested to control the morphological variation of flow features associated with impact craters (Buczkowski et al., 2016; Schmidt et al., 2017). Different types of flow features have been proposed and corresponding planetary analogs have been suggested, including ice-cored flows on Earth, long-runout landslides on Iapetus and rampart ejecta on Ganymede and Mars (Buczkowski et al., 2016; 
Schmidt et al., 2017). Dawn also observed unexpected morphological expressions of possible internal activity. These are exemplified by Ahuna Mons, a $\sim 17 \mathrm{~km}$ wide and $\sim 4 \mathrm{~km}$ high dome, whose morphological features are explained by a cryovolcanic process involving highly viscous extrusions (Ruesch et al., 2016). An additional discovery enabled by Dawn FC observations and specific to the polar areas of Ceres is the identification of permanently shadowed regions (PSRs) in crater interiors where ice could potentially condense from an exosphere or accumulate as a consequence of infalling exogeneous material (Schorghofer et al., 2016; Platz et al., 2016).

The quadrangle area of this study (Ac-1 Asari) is centered on Ceres' North Pole and extends to latitudes down to $65^{\circ} \mathrm{N}$ (Williams et al., 2017). The photo-geologic map presented in this work allows us to investigate the aforementioned features. Relative to areas on Ceres at lower latitudes, the Asari quadrangle is distinguished by the lowest surface temperatures ( $\sim 70 \mathrm{~K}$, e.g., Hayne and Aharonson, 2015) and presence of cold traps. The stability and longevity of subsurface ice increases with increasing latitude (e.g., Hayne and Ahronson, 2015), suggesting that in this study area subsurface ice is potentially closer to the surface than at lower latitudes. These characteristics make the north polar region of Ceres ideal for studying the geology of potential surface and subsurface volatiles.

\section{Method}

Photo-geologic mapping is a discretization of the surface geomorphology into units formed by one or more geologic processes during a certain period of time (e.g., Wilhelms et al., 1987; Tanaka et al., 2009). Visual investigation of morphology, surface texture and roughness, and topography of the entire quadrangle was carried out at a scale of $1: 100,000$. These surface characteristics were used to define several units (also referred to as materials), presented in Section 4.1. Contacts between the units were defined as accurate, approximate, inferred or gradational. The "accurate" contact defines boundaries identified with an accuracy of $100 \mathrm{~m}$ or less along the units. The "approximate" contact was used for the boundary of morphologically muted and degraded units where the uncertainty of the location of the actual contact is estimated to be up to $500 \mathrm{~m}$. The term "inferred contact" was used in shadowed areas, where the uncertainty is as large as the extent of the areas. "Gradational contact" was used to represent the boundary of impact ejecta material, where gradation into adjacent units can occur over a distance of up to $\sim 4 \mathrm{~km}$, and is consistent with the emplacement mechanism of the material. Areal, linear and surface feature classes were used to define specific morphologies found within units. Impact craters are mapped as areal features and are defined as small, if the diameter is in between 5 and $10 \mathrm{~km}$, or as large, if the diameter is larger than $10 \mathrm{~km}$. Linear features have been mapped with a minimum length of $5 \mathrm{~km}$. In addition, a surface feature class is used to map texture variations only, such as a thin layer of mantling material.

The technique used to calculate absolute model ages of units requires crater size-frequency distribution (CSFD) measurements on selected counting areas, in connection with production and chronology functions (Kneissl et al., 2011). In the mapping area, the continuous ejecta blankets of crater materials have the most adequate characteristics for this technique, as they formed in a short period of time without subsequent modification, and present a homogeneous texture. On these units, CSFD measurement areas were selected avoiding crater clusters and shadows. Two sets of production and chronology functions presented in Hiesinger et al. (2016) are used. The derivation of these functions for large objects in the Asteroid Main Belt is described in O'Brien et al. (2014) and in Schmedemann et al. (2014).

\section{Dataset}

The area of quadrangle Ac- 1 Asari covers the North Pole of Ceres down to latitudes of $65^{\circ} \mathrm{N}$ (Williams et al., 2017). For this area Framing Camera (FC) panchromatic images were acquired from the Low Altitude Mapping Orbit (LAMO) with a resolution of $\sim 35 \mathrm{~m} /$ pixel and incidence angle varying from $75^{\circ}$ up to $90^{\circ}$. Raw FC images were calibrated, converted to radiometric units (Schroeder et al., 2014), and ortho-rectified for mosaic production (Roatsch et al., 2016). For photo-geologic mapping and figure production, a linear stretch was applied using 2.5 times the standard deviation of each $\sim 25-\mathrm{km}$ large scene. The longitude system is defined by the $400 \mathrm{~m}$ diameter impact crater Kait (Russell et al., 2016). The nomenclature used in this study was defined by the International Astronomical Union (IAU). Unnamed craters are referred to using letters and their central coordinates. During the mosaicking process, it was unavoidable to use images with some shadowed areas created by the low incidence angle and the variable topography (Fig. 1). In addition to areas in shadow only at the time of the observations, a portion ( $0.13 \%$ of the hemisphere) of them is permanently shadowed (Schorghofer et al., 2016). In these regions photo-geologic mapping was hampered and investigations were performed separately using the reflected light of surrounding terrains (see Section 5.2). The incidence angle of the observations is not optimal for spectral investigations and therefore this study does not include the multi-spectral images acquired by FC. A digital terrain model (DTM) for the area was produced with a 5-step software suite: photo-grammetric block adjustment, multiimage matching, surface point triangulation, digital terrain model generation and base map generation (Preusker et al., 2011, 2015; Jaumann et al., 2012). All elevations are reported relative to an ellipsoid ( 482 by 482 by $446 \mathrm{~km}$ ), unless indicated otherwise.

\section{Results}

\subsection{Map unit description}

The geologic map of quadrangle Asari is illustrated in Fig. 2 and demonstrates the widespread occurrence of the cratered material unit ( $94 \%$ of the quadrangle area) with scattered units related to impact craters. The characteristics of each unit are presented below.

crt-cratered material: Unit characterized by a high density of impact craters of varying degradation states. Crater density for diameter larger than $10 \mathrm{~km}$ is measured at $9.8 \times 10^{-4} \mathrm{~km}^{-2}$. The rim of impact craters have been mapped and distinguished as raised rims of small craters $(5-10 \mathrm{~km})$ and raised rims of large craters $(>10 \mathrm{~km})$ for rim crests appearing sharp at the mapping resolution. Rims lacking a topographic rise and with a highly cratered crest are defined as degraded and have been mapped for crater diameters larger than $5 \mathrm{~km}$. On the crater floors, central peaks reaching heights of $\sim 1 \mathrm{~km}$ relative to the floors, and width up to $\sim 10 \mathrm{~km}$ have been identified and mapped. The topography of this unit is mainly controlled by that of superposing impact craters, as topographic lows are mostly circular and topographic heights are circumferential to the lows. A crater worth mentioning is centered at $66.3^{\circ} \mathrm{E}-6.5^{\circ} \mathrm{N}$ and has a rare concentric property (within arrows in Fig. 1B), i.e., it has a main circular rim with a diameter of $\sim 39 \mathrm{~km}$ containing in its center a smaller and deeper (by $1.2 \mathrm{~km}$ ) subcircular low $\sim 13 \mathrm{~km}$ in diameter. The two craters have a cratered surface and lack raised rims. In a few locations (white areas in Fig. 1B), regions up to $4.5 \mathrm{~km}$ high relative to the surroundings are found sharing their boundaries with two or more impact craters. In these regions, the point of higher elevation is found close to one of the craters rim, as shown in the topographic profile of Fig. 3. Only 

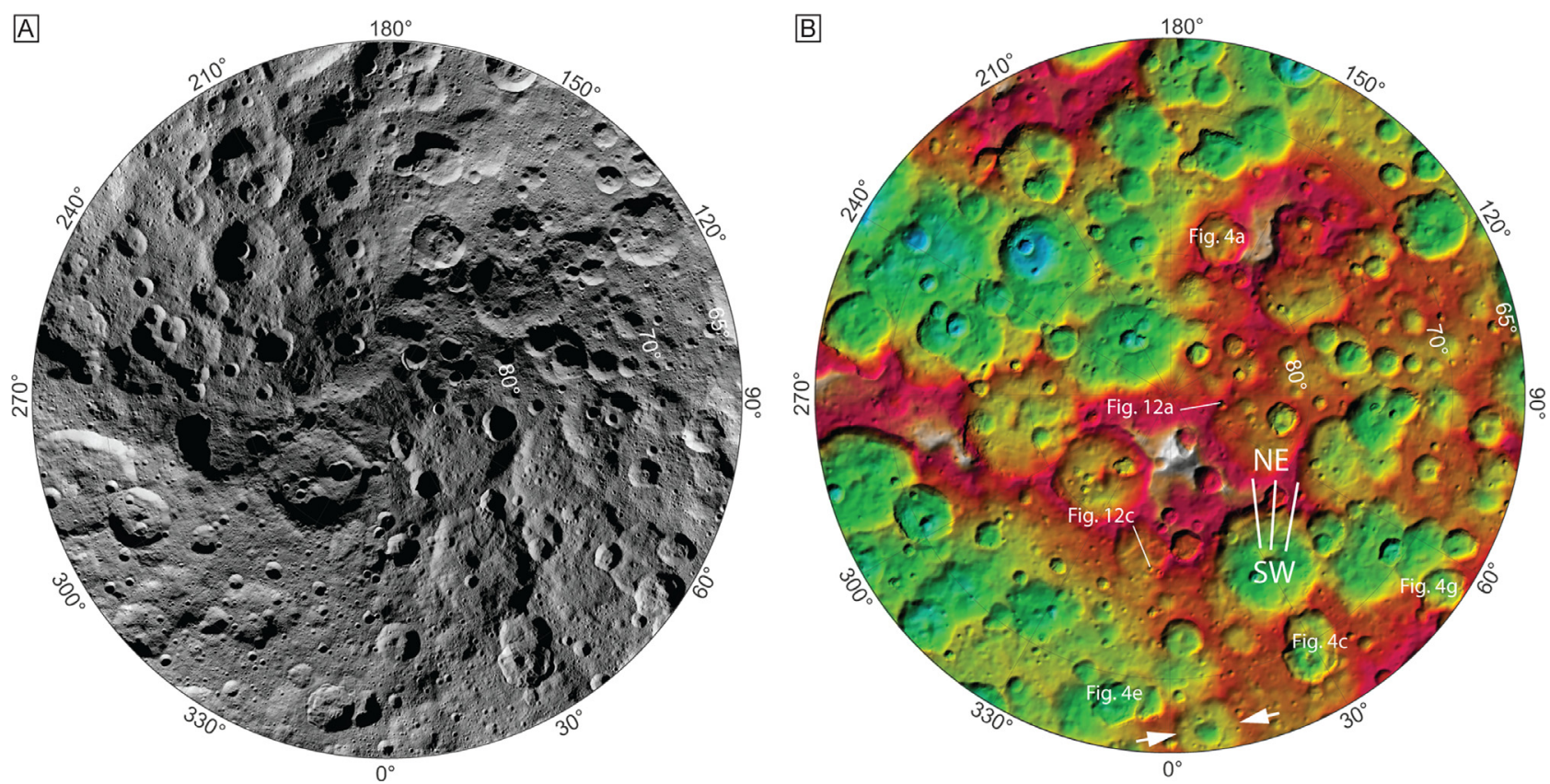

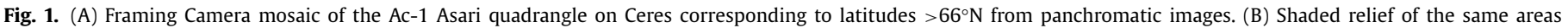

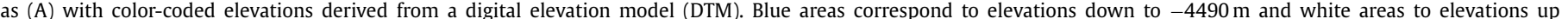

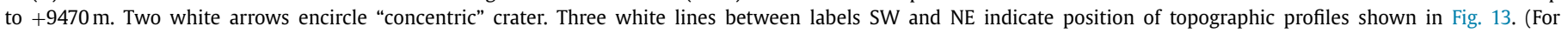
interpretation of the references to color in this figure legend, the reader is referred to the web version of this article.)

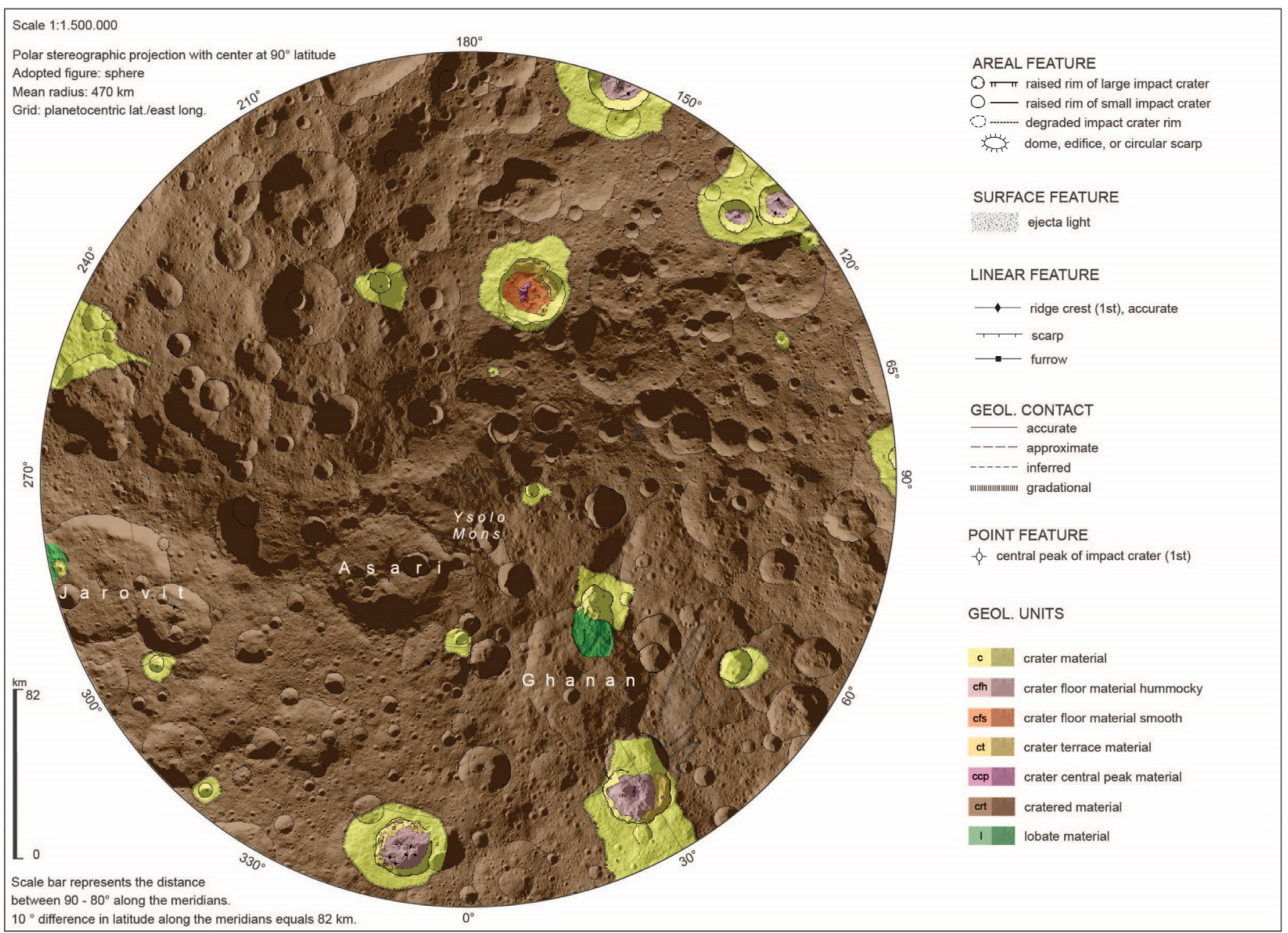

Fig. 2. Geologic map of Ac-1 Asari quadrangle on Ceres in polar stereographic projection and associated legend. Named features are shown. 


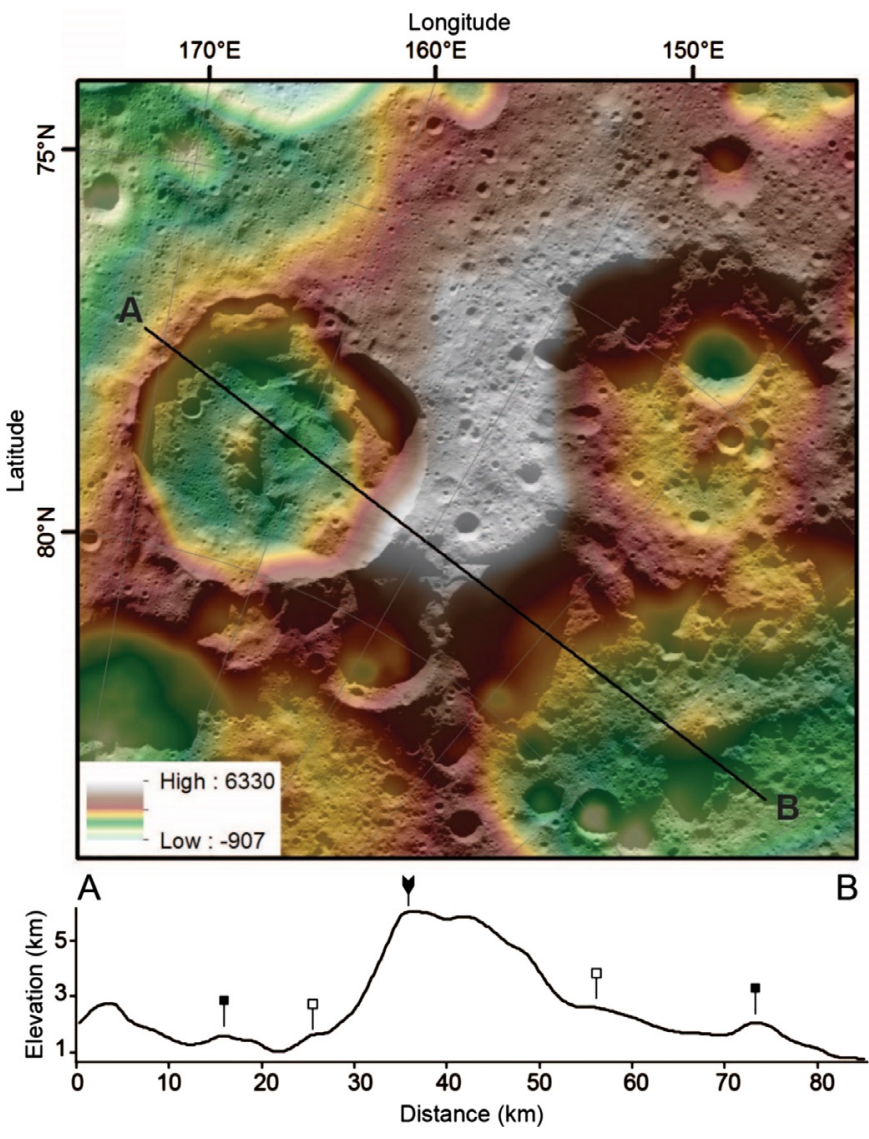

Fig. 3. FC mosaic with color-coded topography and topographic profile across A-B line. The topographic profile crosses two impact craters and a topographic high. Note how the highest point (arrow) is located close to the rim of one of the craters. On the topographic profile, solid squares pinpoint to crater central peaks and void squares to terraces. (For interpretation of the references to color in this figure legend, the reader is referred to the web version of this article.)

one region of high elevation named Yamor Mons has different topographic characteristics, and is mapped as a dome feature.

Interpretation: The density of craters indicates that this unit belongs to the oldest and most widespread terrain on Ceres (Hiesinger et al., 2016). The major process responsible for the formation of this terrain is impact cratering, as is evident from the topographic map. Even the largest topographically low areas (e.g., $280^{\circ} \mathrm{E}-360^{\circ} \mathrm{E}$ ) might be relicts of ancient impact basins (e.g., Marchi et al., 2016). Topographically high regions are possibly accumulations of ejecta and raised rim material from various impacts. The origin of the concentric crater discussed above may be related to the target properties. An impact on a weak layer superposing a stronger layer results in a concentric crater if $D / t_{L}>10$, where $D$ is the main crater diameter and $t_{\mathrm{L}}$ is the weak layer thickness (Melosh, 1989, p. 82). This layered target, if indeed present, is spatially limited because nearby craters of smaller, equal or larger size lack this characteristic. Cryovolcanism is not interpreted to contribute to the formation of craters (e.g., calderas) because nested craters on topographically high areas (e.g., Hiesinger et al., 2016) are not observed. There is no evidence for tectonic deformation such as linear troughs.

dome areal feature: Positive topographic relief not associated with a crater rim and with the same texture as the cratered material unit (i.e., highly cratered surface). Yamor Mons is the only dome feature occurring in the study area at $12^{\circ} \mathrm{E}-86^{\circ} \mathrm{N}$, with an approximately triangular shape in plan view, and reaching a height of $\sim 4.5 \mathrm{~km}$ above the surroundings.
Interpretation: Dome features on Ceres might be cryovolcanic in origin (Ruesch et al., 2016). However, the cratered surface of Yamor Mons lacks pristine morphologies used to support this origin. A detailed description of this unit is presented in Section 5.1.

$c$-crater material: Unit characterizing material inside and outside the raised, sharp-crested rims of craters (Fig. 4). A paucity of superposed impact craters and consequently smoother appearance differentiates this unit from the cratered material unit. The unit also identifies material associated with craters smaller than $5 \mathrm{~km}$ in diameter which were not mapped as raised rim craters: for such cases, the minimum width of the unit is defined at $5 \mathrm{~km}$. Outside the rim, most occurrences of this unit extend for $\sim 1$ crater radius, except for the crater at $28^{\circ} \mathrm{E}-69^{\circ} \mathrm{N}$ (the youngest in the quadrangle, unnamed crater A) which covers a more extensive area (Fig. 4C). Several textures are observed, such as partly overlapping features, ponded deposits and clusters of smaller craters (Fig. 4D). Inside the rim, the unit involves the wall and floor of craters. The walls can display superposed impact craters elongated in the downslope direction or spurs, fan-shaped material and downslope lineations. The contact is gradational with the cratered material unit and approximate with other crater units.

Interpretation: Material exposed by impacts in geologically recent times. Outside the rim, this unit corresponds to the ejecta blanket and to surfaces modified by scouring and secondary impacts. Ponded deposits have the same morphologies as material interpreted to be impact melt on the Moon and Vesta (e.g., Krueger et al., 2016; Williams et al., 2014; Neish et al., 2014; Denevi et al., 2012; Plescia and Cintala, 2012; Bray et al., 2010) and might share the same origin (e.g., Krohn et al., 2016). Buczkowski et al. (2016) identify a similarity between the crater material located north of unnamed crater A $\left(28^{\circ} \mathrm{E}-69^{\circ} \mathrm{N}\right)$ (Fig. $4 \mathrm{C}$ and D) and fluidized ejecta blankets of rampart craters on Mars (Carr et al., 1977; Senft and Stewart, 2008) and Ganymede (Boyce et al., 2010). Fig. 4C and $\mathrm{D}$ shows how the ejecta material (north of unnamed crater $\mathrm{A}$ $\left.\left(28^{\circ} \mathrm{E}-69^{\circ} \mathrm{N}\right)\right)$ is deposited on top of the floor as well as on the wall of a preexisting and juxtaposed crater interior (small arrow Fig. 4C and D). The wall section that faces the source crater of ejecta material is also overlapped by ejecta. In this context a rampart morphology (i.e., increase in topographic relief at the termini of the ejecta) is not observed. Instead, the ejecta morphology and extent is controlled by the preexisting topography of a juxtaposed crater.

cfh-crater floor material hummocky: Unit identified on the floor of morphologically fresh impact craters, juxtaposed to the crater material unit. The relief is irregular displaying few kms long, 50$300 \mathrm{~m}$ high ridges, spaced $\sim 1 \mathrm{~km}$, and boulders up to $\sim 370 \mathrm{~m}$ in size.

Interpretation: Material representing mass wasting accumulation, such as slumped blocks, mostly originating from the crater wall and terraces with a minor debris contribution from the central peak. The presence of this material, together with the crater floor smooth, crater terrace, and crater central peak presented below characterizes a complex crater morphology and distinguishes it from a simple bowl-shaped crater (Hiesinger et al., 2016).

$c f s$-crater floor material smooth: Unit found in the same context as crater floor material hummocky but lacking ridges. The unit has topographic changes lower than $300 \mathrm{~m}$ over a distance of $\sim 4 \mathrm{~km}$. A possible embayment contact on adjacent units appears degraded by impact cratering. The only crater hosting this unit is found at $160^{\circ} \mathrm{E}-78^{\circ} \mathrm{N}$ (unnamed crater B) and has a diameter of $\sim 30 \mathrm{~km}$, the same size as craters hosting crater floor material hummocky.

Interpretation: Possible origins for this unit include mobilized impact melt, impact-triggered volcanism, or cryovolcanism (Hiesigner et al., 2016). This unit is usually found for craters $>40 \mathrm{~km}$ in diameter, together with a central pit, pit clusters and floor fractures (Hiesigner et al., 2016). The formation of this unit 

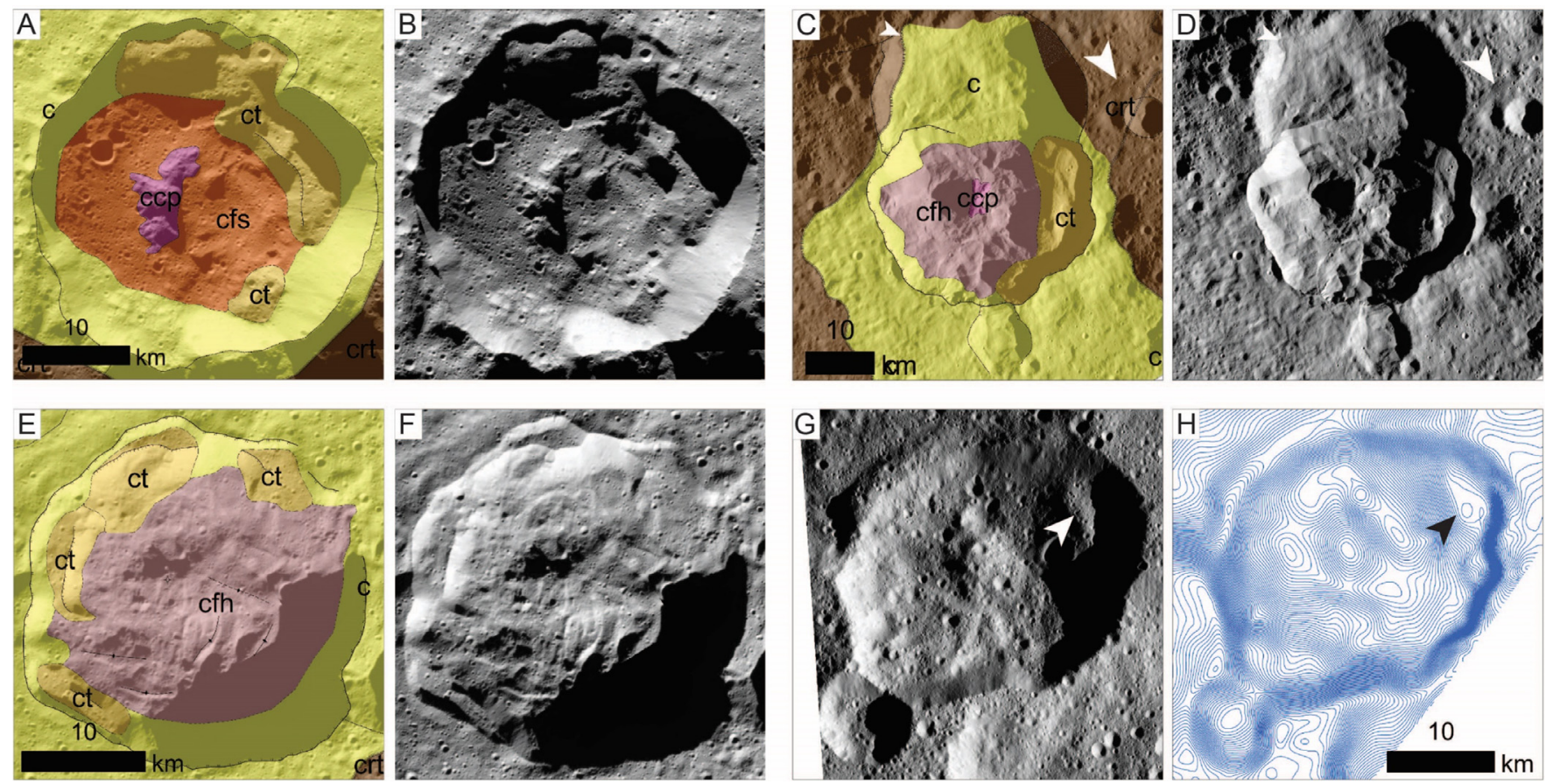

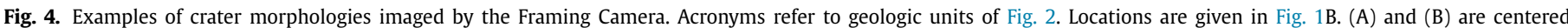

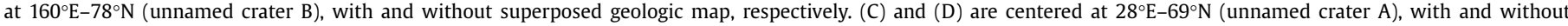

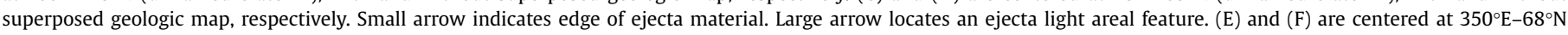

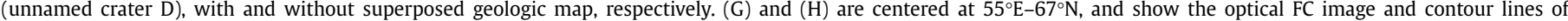

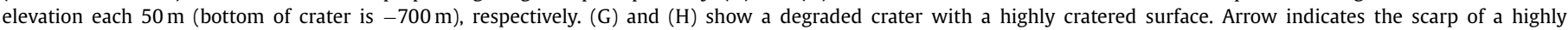
cratered terrace.

instead of a floor dominated by mass wasting deposits might be the consequence of differences in target properties.

ct-crater terrace material: Unit found along the wall of morphologically fresh impact craters, with a step-like scarp and a subhorizontal platform (see topographic profile of Fig. 3). Terraces can occur at multiple discrete locations within a crater, where rim sections are curvilinear and concentric (e.g., Fig. 4A and E). In degraded craters the terraces are modified by superposing craters, but can still be identified by their preserved relief (Fig. $4 \mathrm{H}$ ). This unit is found for crater diameters above $20-25 \mathrm{~km}$.

Interpretation: Mass wasting unit formed as a rotational landslide during the modification stage of complex crater formation (e.g., Melosh, 1989).

ccp-crater central peak material: Single or group of positive relief features approximately located at the center of morphologically fresh craters, distinct in texture from crater wall material (such as lobate material), and displaying a sharp (mapped with an uncertainty of $<100 \mathrm{~m}$ ) contact with adjacent materials. Sharp crests and steep $\left(20^{\circ}\right)$ slopes with downslope lineations are identifiable (Fig. 4A).

Interpretation: Material uplifted from depth during the complex crater formation process (e.g., Melosh, 1989) is the cause of these features. Where the contact with floor material is not recognized, central peaks are identified with a central peak point feature (Fig. 4E).

l-lobate material: Unit characterized by a smooth, sloping surface with longitudinal grooves and with steep margins at the front (in the downslope direction) and on the sides. Upslope, the material has slumped blocks and coincides with the base of a scarp, located in the interior or at the rim of an impact crater. The latter crater is superposed on the rim of a larger, preexisting crater. In planar view, the unit has lobes in the downslope direction, and the width of the marginal scarp is considerably less than the half of the entire lobe width. The steep-sided margins (steeper than the sloping surface) are recognized in Framing Camera images as well as in the High Altitude Mapping Orbit (HAMO) DTM. This material is found within Ghanan and Jarovit craters. Where degraded, the material has a cratered surface: the relief is still preserved and enables its identification and differentiation from crater terrace material which has a sub-horizontal platform (Fig. 4G). Furthermore, the longer axis of the lobate material is perpendicular to the crater rim, whereas the crater terrace material is extended parallel to the rim from which it originates.

Interpretation: Mass wasting deposits originating from the collapse of crater rim material subsequent to an impact probably forms this material. The influence of water ice on the mobilization of the lobate material has been suggested (Buczkowski et al., 2016) and is considered in Section 5.3.

Ejecta light areal feature: Mantling extending outward in a ray pattern from the crater material of a morphologically fresh crater (Fig. 4C) describes these features. The features are brighter than the surroundings and have longitudinal lineaments. For unnamed crater $A\left(28^{\circ} \mathrm{E}-69^{\circ} \mathrm{N}\right)$, the feature extends up to 5 crater radii.

Interpretation: Distal ejecta facies where surface scouring and disturbance by ejecta fragments occurred (e.g., Melosh, 1989).

\subsection{Absolute model ages}

Crater size-frequency distribution (CSFD) measurements (Fig. 5, Table 1) were performed on continuous ejecta blankets of craters (Fig. 6) centered at the following coordinates: unnamed crater A at $28^{\circ} \mathrm{E}-69^{\circ} \mathrm{N}$, unnamed crater $\mathrm{B}$ at $160^{\circ} \mathrm{E}-78^{\circ} \mathrm{N}$, unnamed crater $\mathrm{C}$ at $48^{\circ} \mathrm{E}-78^{\circ} \mathrm{N}$, unnamed crater $\mathrm{D}$ at $350^{\circ} \mathrm{E}-68^{\circ} \mathrm{N}$ and unnamed crater $\mathrm{E}$ at $135^{\circ} \mathrm{E}-68^{\circ} \mathrm{N}$. Overall, we found that the superimposed crater size-frequency distributions have a similar shape as the Lunar Derived Model (LDM) production function, aside from a higher density of craters at larger diameters which can be explained by pre-existing impacts, and the resolution rollover at 

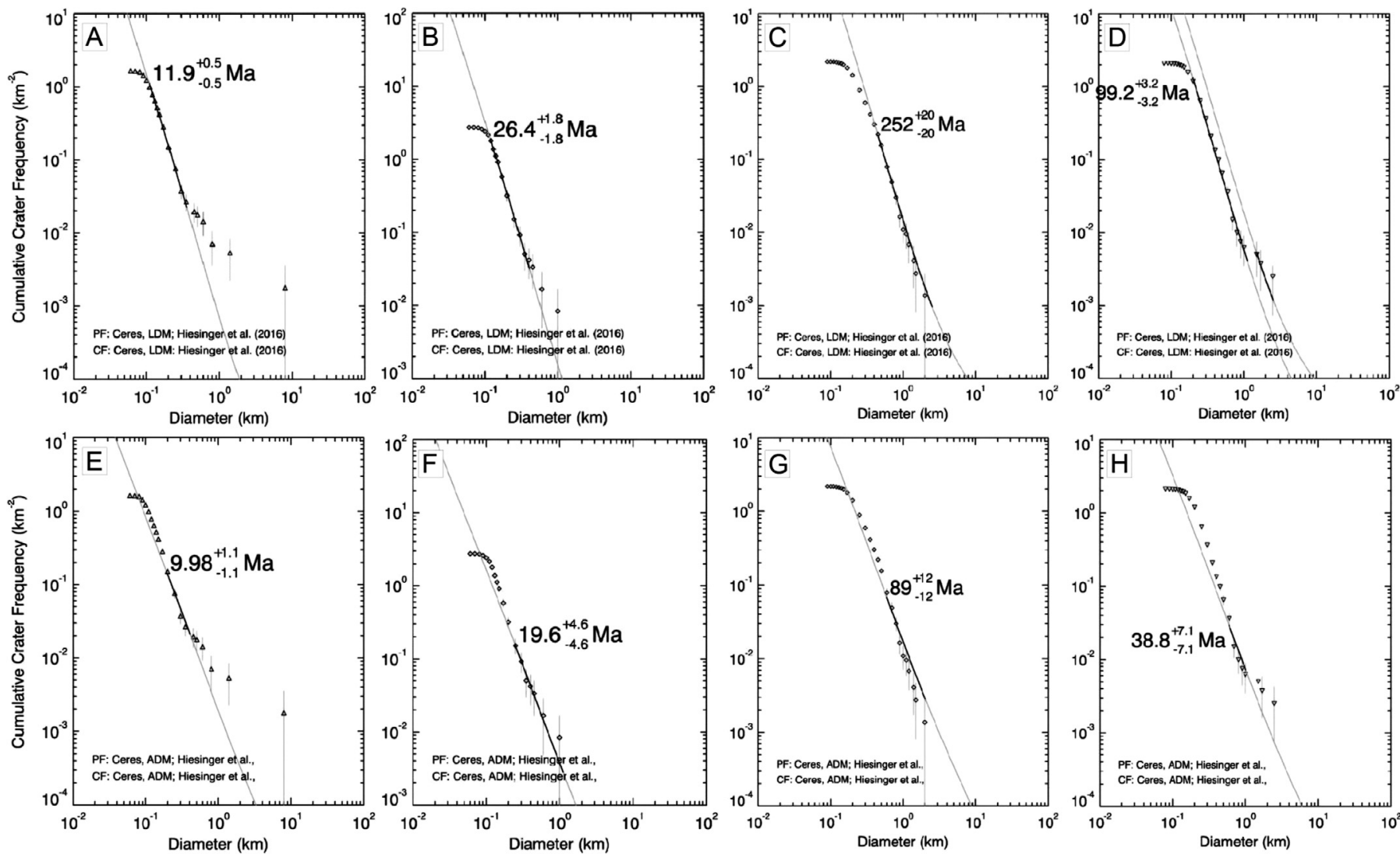

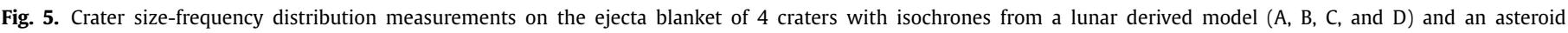

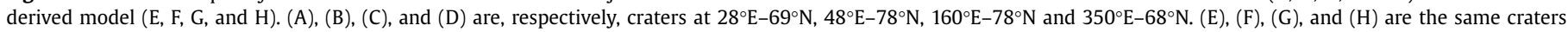
as in the sequence $\mathrm{A}, \mathrm{B}, \mathrm{C}$, and $\mathrm{D}$.

Table 1

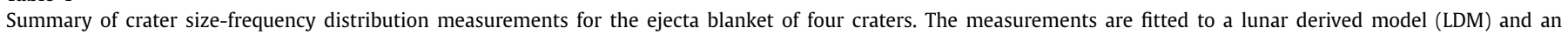
asteroid derived model (ADM) described in Hiesinger et al. (2016).

\begin{tabular}{|c|c|c|c|c|c|c|c|c|c|c|c|}
\hline \multirow[b]{2}{*}{$\begin{array}{l}\text { Ejecta } \\
\text { blanket } \\
\text { location }\end{array}$} & \multirow[b]{2}{*}{$\begin{array}{l}\text { Count area } \\
\left(\mathrm{km}^{2}\right)\end{array}$} & \multicolumn{5}{|l|}{ LDM } & \multicolumn{5}{|l|}{ ADM } \\
\hline & & $\begin{array}{l}\text { Ncum } \\
(\geq 1 \mathrm{~km})\end{array}$ & $\begin{array}{l}\text { Error on } \\
\text { Ncum } \\
(\geq 1 \mathrm{~km})\end{array}$ & $\begin{array}{l}\text { No. crater } \\
\text { fitted }\end{array}$ & AMA (Ma) & $\begin{array}{l}\text { Error on } \\
\text { AMA (Ma) }\end{array}$ & $\begin{array}{l}\text { Ncum } \\
(\geq 1 \mathrm{~km})\end{array}$ & $\begin{array}{l}\text { Error on } \\
\text { Ncum } \\
(\geq 1 \mathrm{~km})\end{array}$ & $\begin{array}{l}\text { No. crater } \\
\text { fitted }\end{array}$ & AMA (Ma) & $\begin{array}{l}\text { Error on } \\
\text { AMA (Ma) }\end{array}$ \\
\hline $28 \mathrm{E}-69 \mathrm{~N}$ & 563 & $6.92 \mathrm{E}-04$ & $2.96 \mathrm{E}-05$ & 546 & 12 & 1 & $1.90 \mathrm{E}-03$ & $2.21 \mathrm{E}-04$ & 74 & 10 & 1 \\
\hline $48 \mathrm{E}-78 \mathrm{~N}$ & 119 & $1.54 \mathrm{E}-03$ & $1.07 \mathrm{E}-04$ & 209 & 26 & 2 & $3.74 \mathrm{E}-03$ & $8.82 \mathrm{E}-04$ & 18 & 20 & 5 \\
\hline $160 \mathrm{E}-78 \mathrm{~N}$ & 731 & $1.47 \mathrm{E}-02$ & $1.15 \mathrm{E}-03$ & 162 & 252 & 20 & $1.70 \mathrm{E}-02$ & $2.25 \mathrm{E}-03$ & 57 & 89 & 12 \\
\hline $350 \mathrm{E}-68 \mathrm{~N}$ & 801 & $5.79 \mathrm{E}-03$ & $1.88 \mathrm{E}-04$ & 948 & 99 & 3 & $7.39 \mathrm{E}-03$ & $1.51 \mathrm{E}-03$ & 24 & 39 & 7 \\
\hline
\end{tabular}

smaller diameters (Fig. 5). The Asteroid Derived Model (ADM) production function consistently models a lower density of impact craters with decreasing diameters relative to the measured CSFD (Fig. 5). Because of the differences between CSFD measurements and the ADM production function, the diameter range for the application of the ADM is less constrained than for the LDM (Fig. 5) and therefore only LDM absolute model ages for the craters are presented in the stratigraphic summary of Fig. 7. The oldest measurable age is $\sim 252 \pm 20 \mathrm{Ma}$ for the unnamed crater $\mathrm{B}$ at $160^{\circ} \mathrm{E}-$ $78^{\circ} \mathrm{N}$, the youngest is $12 \pm 1 \mathrm{Ma}$ for the unnamed crater A at $28^{\circ} \mathrm{E}-$ $69^{\circ} \mathrm{N}$ with extensive ejecta and ejecta rays. For the unnamed crater $\mathrm{E}$ at $135^{\circ} \mathrm{E}-68^{\circ} \mathrm{N}$, discrepancies between the CSFD and both LDM and ADM production functions were found preventing the calculation of an absolute model age.

\subsection{Stratigraphy}

The material units of the quadrangle can broadly divided into an old unit, i.e., the widespread cratered material unit with con- temporaneous Yamor Mons and young units related to impact events up to $\sim 30 \mathrm{~km}$ in diameter, for which an absolute model age has been derived. Differences between the CSFD measurements of the young craters and the ADM production function might be explained by evoking two conditions proper to Ceres. Relative to the rock-dominated, ice-free Vesta, the density of Ceres' outermost shell is less constrained, and might lead to incorrect assumptions for the target properties. The range between minimum impact velocity $(\sim 150 \mathrm{~m} / \mathrm{s})$ and escape velocity $(\sim 519 \mathrm{~m} / \mathrm{s})$ on Ceres is larger than at Vesta $(369 \mathrm{~m} / \mathrm{s}$ versus $213 \mathrm{~m} / \mathrm{s}$ ) and thus more favorable for secondary cratering. The contribution of distant, non-clustered secondary craters might affect the measured crater-size-frequency distributions. However, we note that similar discrepancies between the ADM production function and CSFD measurements were found on Vesta (e.g., Kneissl et al., 2014; Ruesch et al., 2014), and thus the influence of conditions proper to Ceres on the CSFD measurements is considered minor. Future improvements on the production functions (e.g., O'Brien et al., 2014; Schmedemann et al., 2014; Ivanov, 2001) should need to take these differences into account. 

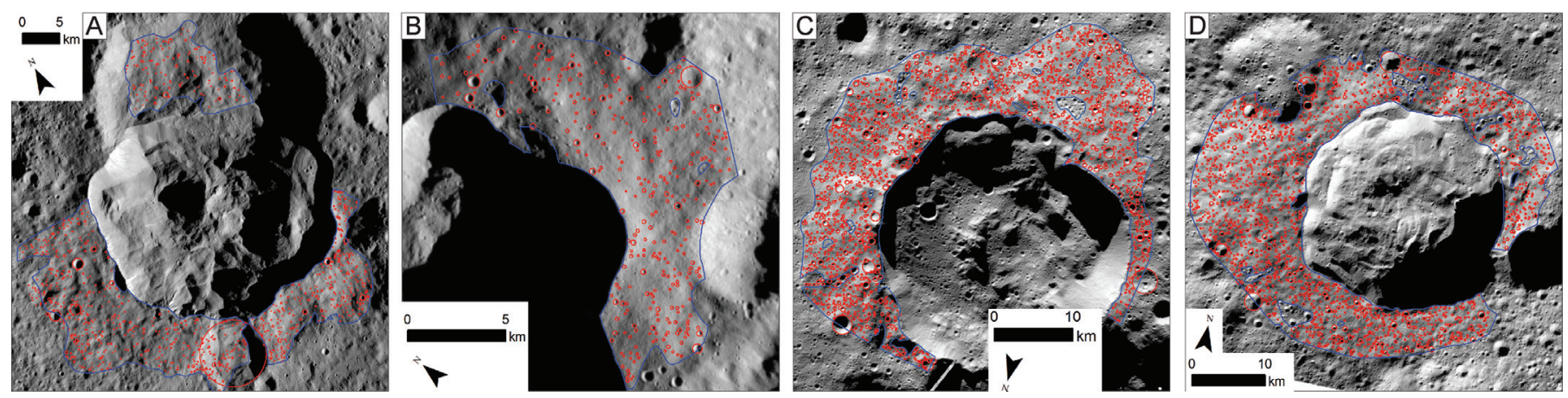

Fig. 6. Crater size measurements for (A) crater at $28^{\circ} \mathrm{E}-69^{\circ} \mathrm{N},(\mathrm{B})$ crater at $48^{\circ} \mathrm{E}-78^{\circ} \mathrm{N}$, (C) crater at $160^{\circ} \mathrm{E}-78^{\circ} \mathrm{N}$ and $(\mathrm{D}) \mathrm{crater}$ at $350^{\circ} \mathrm{E}-68^{\circ} \mathrm{N}$.

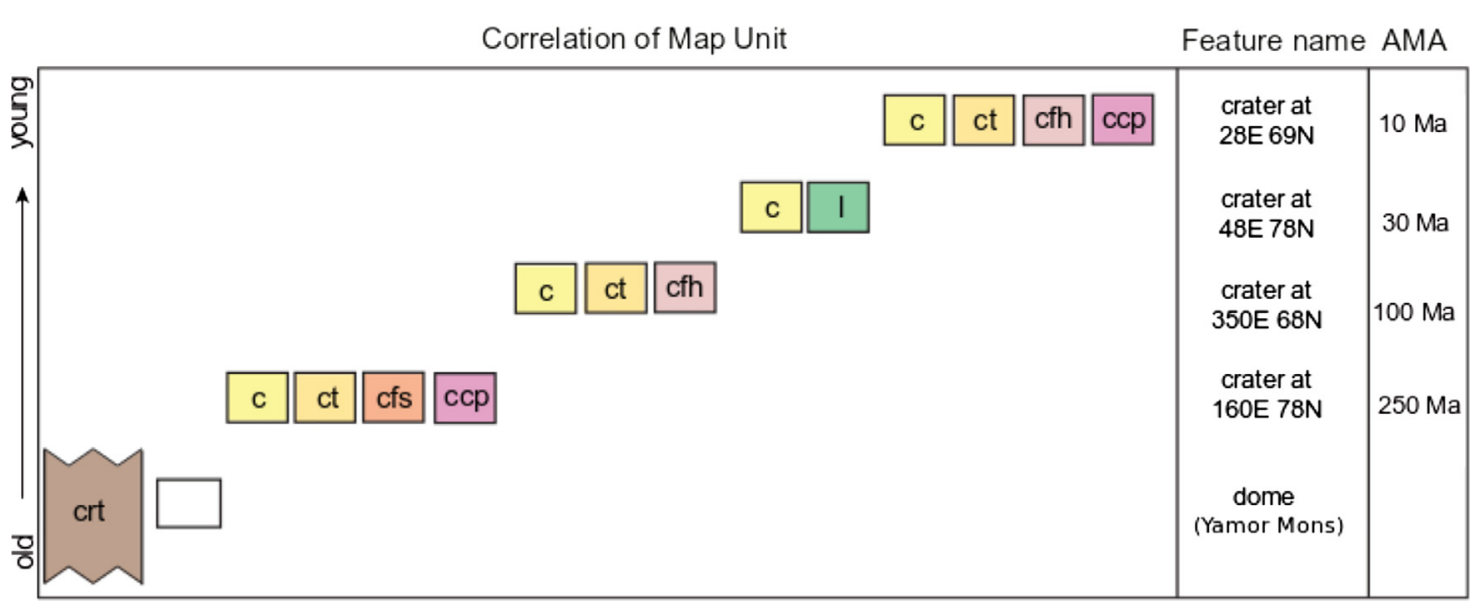

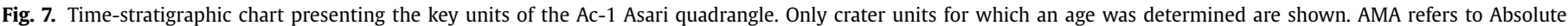
Model Ages derived with the Lunar Derived Model.

\section{Highlighted features}

\subsection{Yamor Mons}

Yamor Mons has an approximately $25 \times 15 \mathrm{~km}$ triangular shape in plan view, an elevation of $9.5 \mathrm{~km}$ relative to the ellipsoid, or $4.5 \mathrm{~km}$ relative to surrounding terrains, and four main $20^{\circ}-40^{\circ}$ steep walls oriented approximately northeast, east, south and northwest. In the summit area, the highest elevation is reached by an elongated $4 \mathrm{~km}$ long peak oriented northwest-southeast. A relatively flat area approximately $1 \mathrm{~km}$ wide is found west of the ridge (Fig. 8).

The northeast wall has a relatively constant slope of $35^{\circ}-40^{\circ}$, the highest of all flanks (profiles in Fig. 9). The bottom of the northeast profile is concave upward, a characteristic shared by all the flanks of the dome. Most of the east wall has a slope of $\sim 30^{\circ}$ slightly decreasing near the summit, creating a slightly concave downward profile. The south wall has two distinct sections: the eastern side of the south wall, has a relatively constant slope of $\sim 24^{\circ}$ (profile S2 in Fig. 9), whereas the western side has a concave downward profile (S1 in Fig. 9). The northwest wall is the least steep of the dome flanks, with a maximum of $\sim 20^{\circ}$. The slope slightly decreases near the summit (starting $\sim 3 \mathrm{~km}$ before highest point), similar to the east profile.

In addition to these main walls, the dome topography is affected by three impact structures (Fig. 8). The smaller of the three craters, approximately $8 \mathrm{~km}$ large and located west of the dome summit, affected the flanks with its entire diameter, leading to an asymmetric crater morphology controlled by the sloped surface, as described by Krohn et al. (2014). The second, $\sim 18 \mathrm{~km}$ large crater only partly impacted on the dome flanks; the northwest section of the crater wall corresponds to an additional, smaller dome wall facing southeast and with an arcuate shape in plan view. The flank modifications possibly created by the third crater, $\sim 13 \mathrm{~km}$ in diameter and located north of the dome, differ from the previous two. A larger proportion of the dome flank appears to have been affected by the impact. The southern section of the crater wall does not follow a circular rim, as for the $\sim 18 \mathrm{~km}$ large crater, instead it extends all the way up to the dome summit crest. The resulting NE facing flank's steepness is higher than adjacent flanks.

Fig. 10 shows the highly cratered texture of the dome. Small impact craters on the steepest walls (NE and $\mathrm{E}$ ) have a downslope elliptical shape, more pronounced than on the south and northwest walls. Note how the northeast wall lacks smaller craters identifiable on the other walls, possibly the result of erased craters by extensive mass wasting on the steep surface. Beside impact craters, no other morphological features are identifiable.

\subsection{Shadowed areas}

The areas lacking direct solar illumination during the observation campaign usually coincide with the bottoms and walls of impact craters. To investigate the shadowed areas, the Low Altitude Mapping Orbit (LAMO) mosaic (Roatsch et al., 2016) and LAMO single images have been stretched to highlight only the variation within the lowermost digital numbers (DN) (200-900 DN) acquired by the FC and representing multi-scattered light reflected by the shadowed areas. The quality of the images within these areas varies considerably, depending, among others things, on the presence and size of the illuminating surface, e.g., the directly illuminated crater wall. For the most strongly, indirectly illuminated areas, impact craters and central mounds can be 

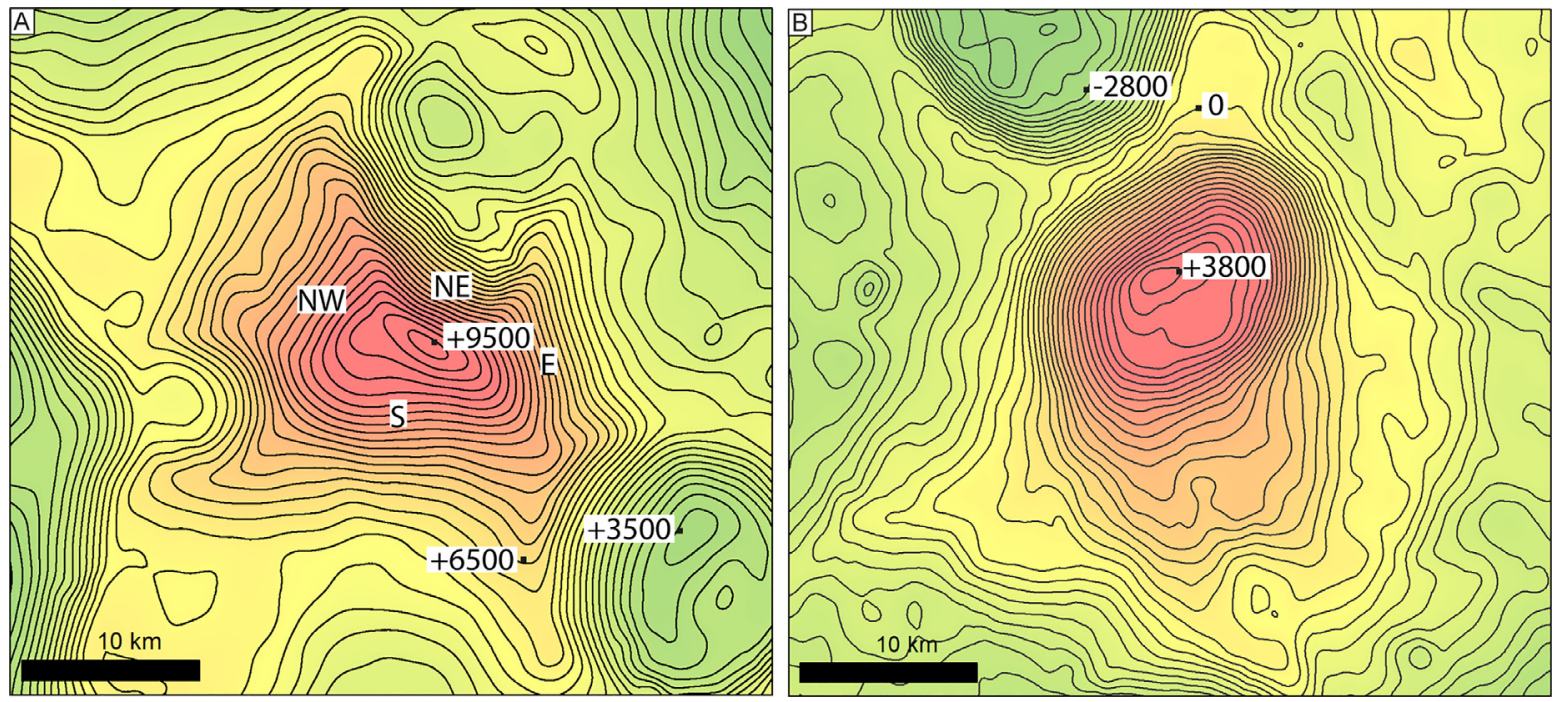

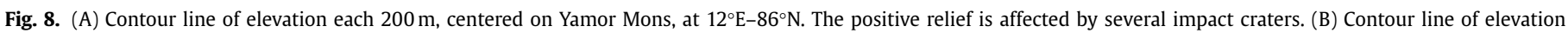
each $200 \mathrm{~m}$ centered on Ahuna Mons, $316^{\circ} \mathrm{E}-10^{\circ} \mathrm{S}$ (outside the Ac- 1 quadrangle).

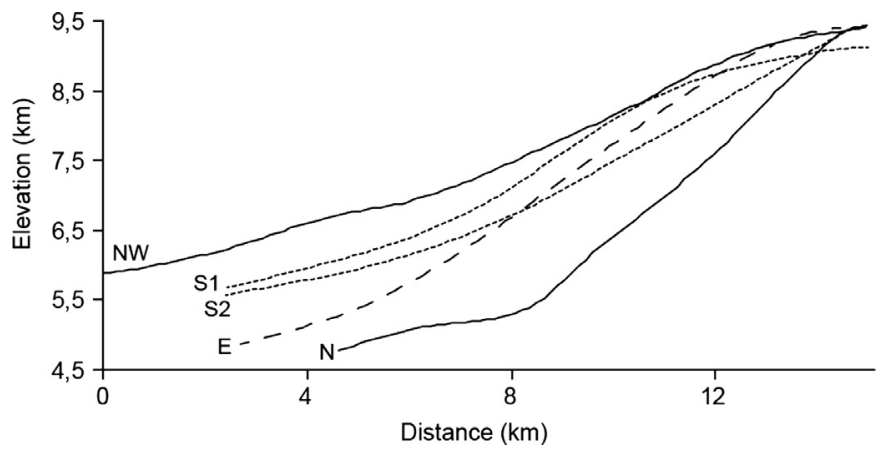

Fig. 9. Topographic profiles of the flanks of Yamor Mons. Labels refer to the orientation of the flanks. For the south-facing side, two profiles (S1 and S2) are shown.

identified. Features within shadowed areas have been compared to permanently shadowed regions (PSRs) identified and mapped by Schorghofer et al. (2016). This was performed by investigating the LAMO mosaic at low DN. Of the $\sim 100$ PSRs, two hosted a circular area of higher $(\sim 350 \mathrm{DN})$ reflectance $\left(353.5^{\circ} \mathrm{E}-77.5^{\circ} \mathrm{N}, 78.5^{\circ} \mathrm{E}-\right.$ $86.1^{\circ} \mathrm{N}$ ) (Fig. 11). Because the mosaic was not developed for such investigations, the original, high spatial resolution of low DN pixels was not completely preserved during mosaic production. To confirm that the rarity of brighter areas associated with PSRs ( $2 \%)$ is real and not due to the resolution of the mosaic, 15 randomly selected PSRs have been investigated with single LAMO images. No additional circular brighter areas were detected, neither were areas darker than the surrounding.

The two brighter areas range in size between 1.0 and $1.5 \mathrm{~km}$ and lie within PSRs ranging in size from $\sim 2$ to $\sim 3 \mathrm{~km}$ (Fig. 11A, $B$ and $C, D$ ). The lower spatial resolution of the PSR extension prevents a detailed comparison between the boundaries of the PSRs and the brighter areas. We note, however, that the associated PSRs are relatively small compared to other regions a dozen of $\mathrm{km}$ wide. The hosting simple bowl-shaped craters are 4.8 and $6.5 \mathrm{~km}$ in diameter, have an aspect ratio of $\sim 1 / 5$ and $\sim 1 / 7$, and are both morphologically fresh with sharp rim crest and an ejecta blanket. The brighter areas are located at the bottom of the craters, with their center slightly $(\sim 500 \mathrm{~m})$ offset toward the west relative to the deepest point of the floor. Their shape is circular to irregular, with a boundary varying from gradational (across $\sim 600 \mathrm{~m}$, i.e.,
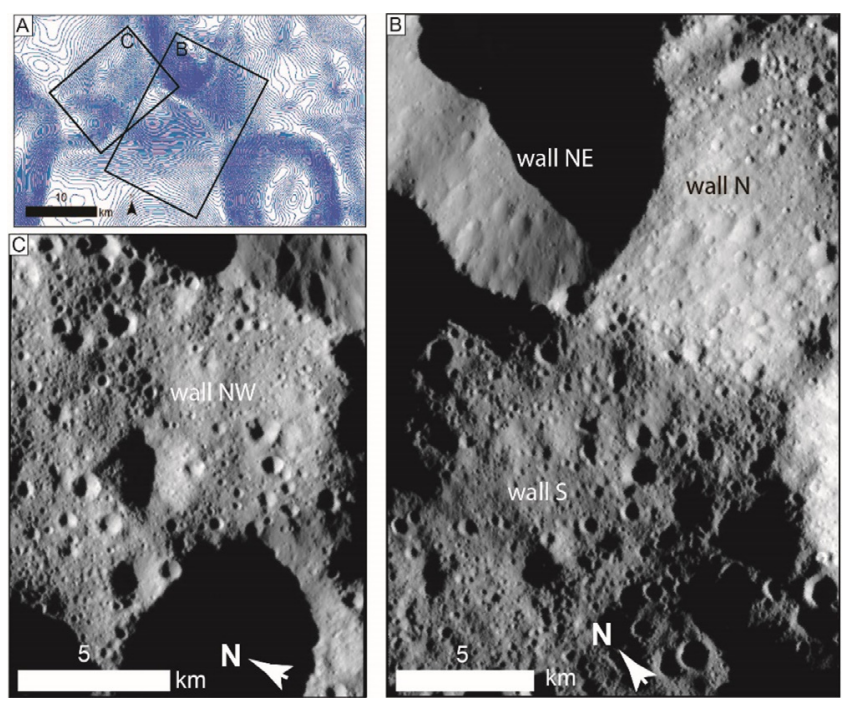

Fig. 10. (A) Location of close-ups on the contour line (each $50 \mathrm{~m}$ ) elevation map centered on Yamor Mons. (B) FC LAMO image of the northeast, east and south walls of Yamor Mons. The south part of the elongated peak is in shadow. (C) FC LAMO image of the northwest wall of Yamor Mons.

16 pixels) to sharp (across $\sim 300 \mathrm{~m}$, i.e., eight pixels) toward darker zones ( $\mathrm{DN}<310$ ) of sloped floor and wall material (Fig. 11E). Sharp contacts are observed where darker downslope streaks reach, and even overlap, the brighter areas (arrow in Fig. 11C). We note that brighter streaks are identifiable as well (Fig. 11C). Within the brighter areas, few possible craters up to $\sim 240 \mathrm{~m}$ are identified by their characteristic brighter and darker side of the wall (Fig. 11E). Each side of the wall has a minimum of two pixels width. Ejecta material is expected to be two pixels wide (one crater radius) but was not observed. Crater rims are expected to be below one pixel size and are thus below the detection level of the available images. Possible darker lineaments of four pixel width (referred to as troughs in Fig. 11) are observed extending for $10-15$ pixels from the area's edge toward the interior.

\subsection{Ghanan lobate material}

Another relevant feature of the North Pole quadrangle is the lobate material found within the $\sim 70 \mathrm{~km}$ large Ghanan crater. The 

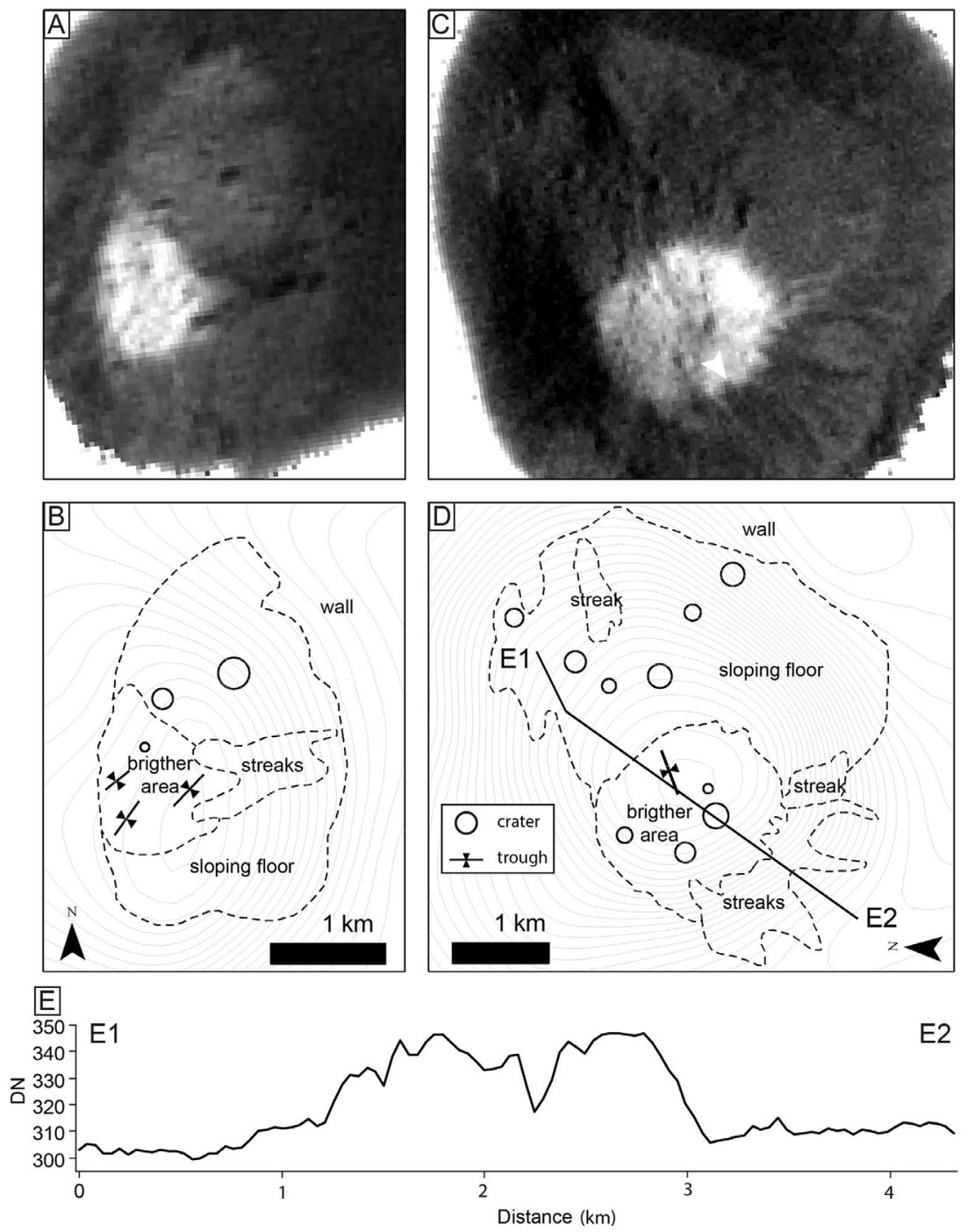

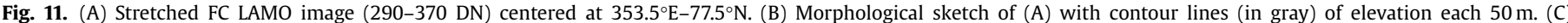

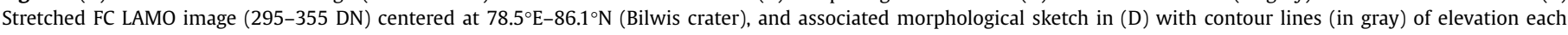
$50 \mathrm{~m}$. E1 and E2 indicate the location of the profile in (E). (E) FC LAMO image profile across the brighter area. Note the variation around distance $2.2 \mathrm{~km}$.

morphologically fresh appearance of the lobate material enables detailed morphometric and morphologic investigations, which in turn shed insights into its formation process. The 23-km long and 20 -km wide lobate material extends from the rim of a $\sim 15-\mathrm{km}$ large crater downslope on the Ghanan crater's interior. The smaller crater is superposed on the NE rim section of the larger Ghanan crater.

A survey of crater superposition indicates that morphologies resulting from an impact near the rim of a larger preexisting crater falls broadly into two categories, depending on where exactly the impact occurs. Where the new impact occurs mostly on the preexisting crater wall, i.e., on a sloped surface, only a smooth rim will develop downslope. In this first case, the morphologies will be similar to those of an asymmetric crater described in Krohn et al. (2014) with a smooth rim section downslope and a sharp rim section upslope. Where the new impact occurs on the preexisting rim, a new, relatively sharp rim between the interiors of the new and old craters will form. The Ghanan superposed crater belongs to this latter category: a sharp rim is clearly identifiable in the topographic profile across the crater (Fig. 12). The newly formed (southwest) downslope rim section of the superposed crater is $\sim 3 \mathrm{~km}$ in elevation, instead of the $4-5 \mathrm{~km}$ of the preexisting Ghanan rim. The preexisting crater interior flanks visible northwest and southeast of the lobate material present two subdued terraces (1 identifiable in the profiles of Fig. 12) and have an average slope of $15^{\circ}$. The lobate material on the preexisting crater flank has a shallower slope of $11^{\circ}$.

The morphology of the Ghanan lobate material is here described from the superposed crater in the downslope direction. The ejecta blanket, sharp rim crest and brighter wall spurs of the superposed crater are clearly identifiable and give to it a morphologically fresh appearance (Fig. 13B). The crater interior is hummocky with slumped blocks. The southwest downslope rim section consists of a set of individual ridges with sharp crests (Fig. 13C). The longest ridge segment displays brighter spurs on its crest, starts directly from the non-collapsed Ghanan rim and extends for $9 \mathrm{~km}$ in the northwest direction. Its flank facing NE toward the interior of the superposed crater is $\sim 24^{\circ}$ steep, whereas the flank facing southwest is approximately $10^{\circ}$ steeper. At the base of the latter flank, the proper lobate material unit starts and extends downslope toward the center of Ghanan crater. Several shorter $(1.5 \mathrm{~km}$ long) ridges complete the southwest downslope rim section. The sides of the ridges present several slumped blocks (their scarps are shown in Fig. 13C), that are source regions of deposits terminating 


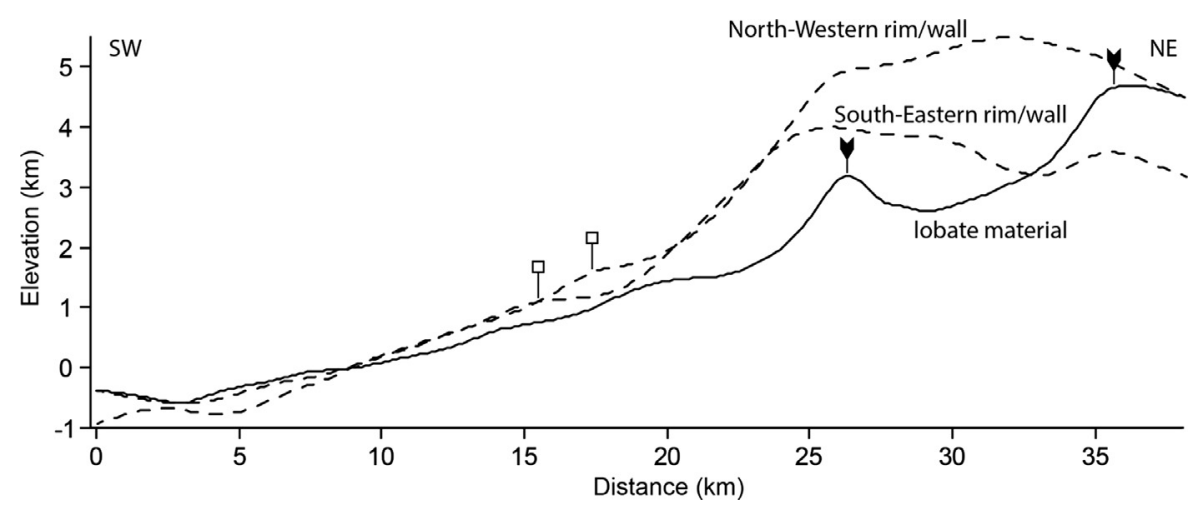

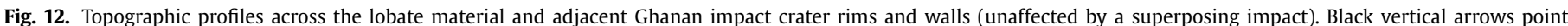

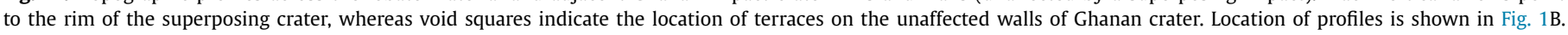
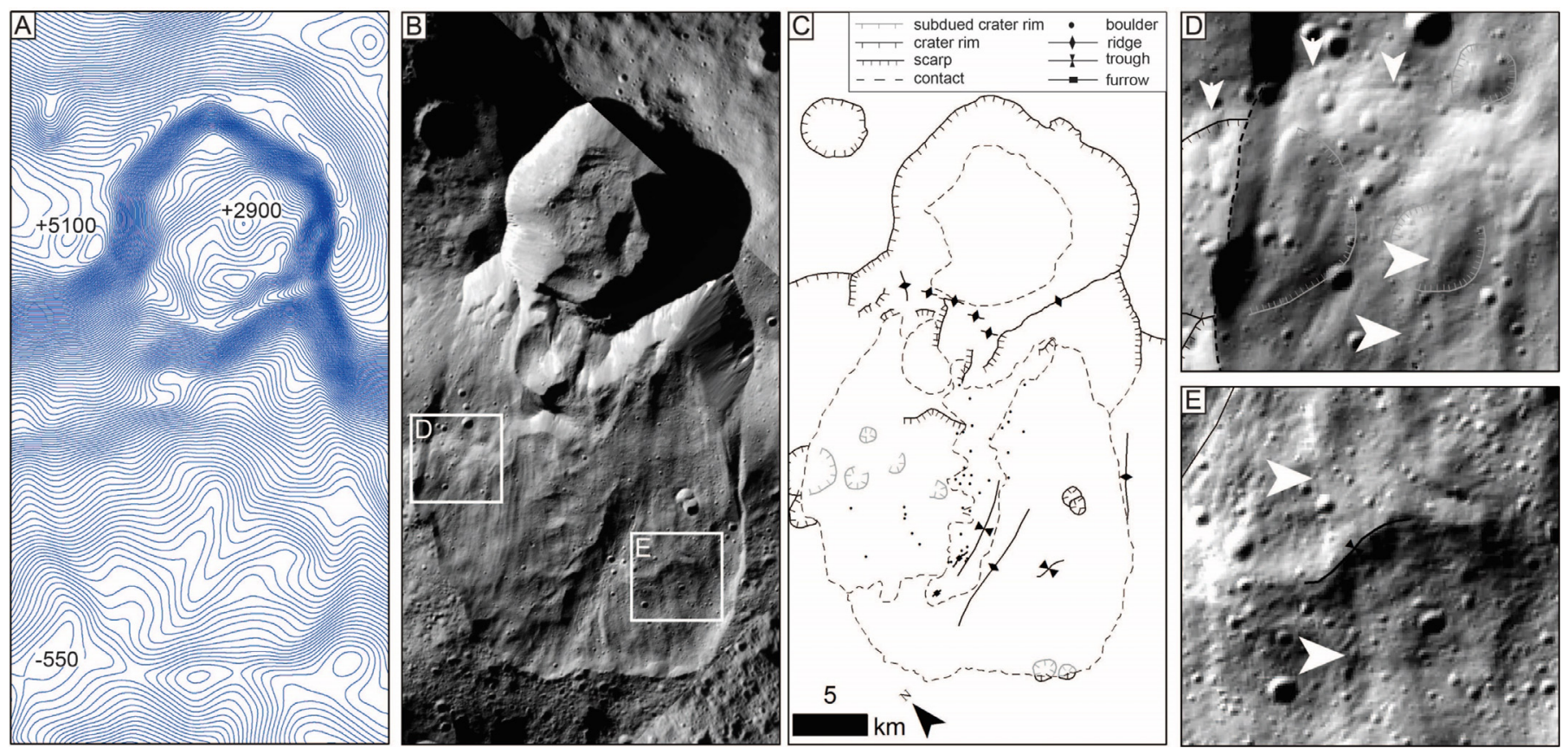

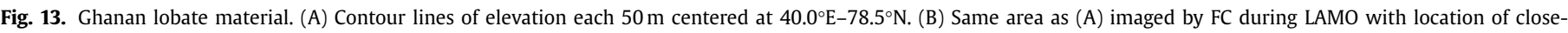

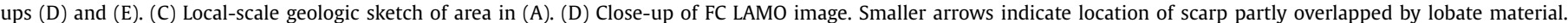

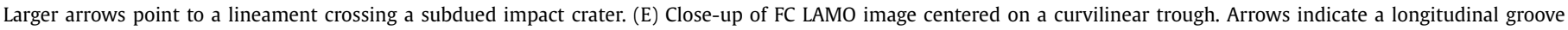
crossing the trough. (D) and (E) are $6.5 \mathrm{~km}$ wide.

several $\mathrm{km}$ downslope and mapped as a single lobate material unit in the quadrangle map of Fig. 2.

As shown in the local scale map of Fig. 13C, four main subunits have been distinguished within the lobate material mapped as a single unit in the regional scale map of Fig. 2. The contacts between them are subdued and prevent unambiguous determination of the stratigraphic relationship. Therefore the sub-units sequence presented here is proposed and is not considered definitive. The probable stratigraphically lower unit is the most extensive and dominates the southern area of the lobate material (Fig. 13C). Close to the downslope terminus, subdued lineaments parallel to the downslope direction are spaced a minimum of $\sim 600 \mathrm{~m}$ and are a few $\mathrm{km}$ in length. This unit hosts a $9 \mathrm{~km}$ long, $2 \mathrm{~km}$ wide and $100-150 \mathrm{~m}$ high ridge, with an orientation slightly tilted relative to the lineaments. A ridge is found along the eastern side of this subunit, similar to a half-side levee. The stratigraphically higher and second most extensive unit is located on the northern area of the lobate material and has a smoother appearance relative to the previous unit (Fig. 13C). The unit warps several craters identifiable as rimless circular topographic lows ("covered" crater), the largest be- ing $1.6 \mathrm{~km}$ in diameter (see crater symbols Fig. 13D). A preexisting terrace identifiable outside the flow can be followed beneath the unit where it is mantled by the unit (see small arrows Fig. 13D). The latter terrace separates the unit in an upslope lineament-free area and a downhill area with closely spaced (minimum spacing of $\sim 400 \mathrm{~m}$ ), slightly curvilinear lineaments oriented in the downslope direction. These two sub-units (Fig. 13D) terminate abruptly in lobate and sharp ( $<100 \mathrm{~m}$ uncertainty) contacts with the surrounding Ghanan crater interior. Images at very low illumination $\left(20^{\circ}\right.$ above the horizon) reveal how the lineaments consist of low relief $(<50 \mathrm{~m})$ troughs and ridges, that run unaffected across the underlying topography, as indicated in Fig. 13D and E.

A superposed sub-unit is located in a narrow area at the center of the lobate material and has more irregular borders and a concentration of boulders relative to the other units (Fig. 13D). It hosts a $7 \mathrm{~km}$ long, $1.6 \mathrm{~km}$ wide and $50-100 \mathrm{~m}$ deep trough parallel to the previously mentioned ridge, as well as a discontinuous smaller furrow, whose largest segment is $2 \mathrm{~km}$ long and $400 \mathrm{~m}$ wide. This unit fills topographic lows of the previous unit that possibly represent underlying terraces of the Ghanan wall (Fig. 13C). Possibly 


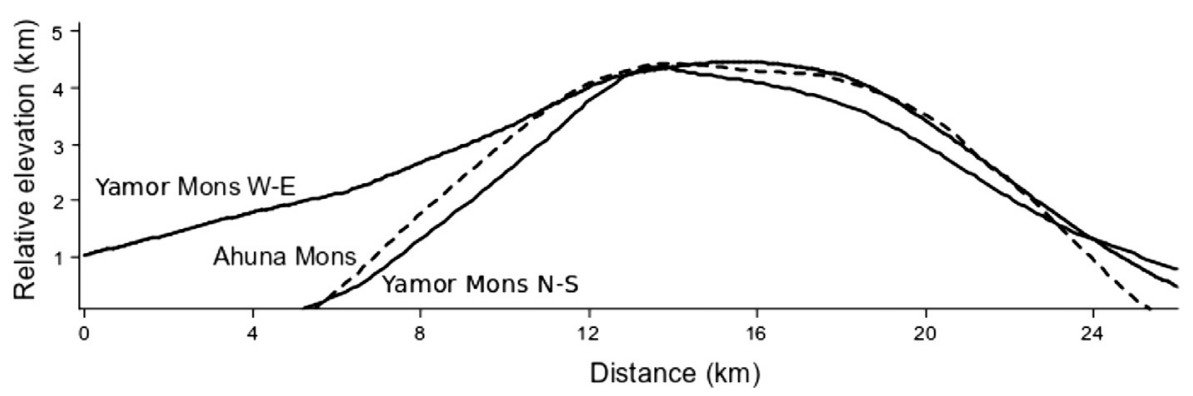

Fig. 14. Topographic profiles across Yamor Mons (W-E and N-S) and across Ahuna Mons in the W-E direction.

postdating the unit is a small $\sim 3 \mathrm{~km}$ wide lobate area close to a slumped block of the southwest rim section.

A different set of lineaments with a radial distribution from the superposed crater are recognized at the northern intersection between the rim scarps of Ghanan crater and the superposed crater (Fig. 13B). They might indicate deposition and/or scouring by ejecta material of the superposed crater on top of the Ghanan rim as well as on the lobate material.

Three features can be used for thickness estimates of the lobate material: (i) the widths measured from nadir and slopes of the lobe fronts indicate an average of $330 \mathrm{~m}$ thickness at the toe, (ii) at another location, the partial filling of a preexisting $1.6 \mathrm{~km}$ large crater sets a maximum thickness of $320 \mathrm{~m}$, assuming a crater depth to diameter ratio of $1 / 5$, (iii) the warping and uncomplete burial of a terrace sets a maximum thickness equal to the elevation difference of $400 \mathrm{~m}$.

\section{Discussion}

\subsection{Montes}

Ahuna Mons is a dome feature close to the equator with comparable size and elevation to Yamor Mons (Fig. 14), and proposed to be cryovolcanic in origin (Ruesch et al., 2016). The dome has an elliptical basal shape of 21 by $13 \mathrm{~km}$ and reaches an elevation of $\sim 4 \mathrm{~km}$ relative to surrounding terrains. There are resemblances between the topographic profiles of the two montes (Fig. 14) that could favor a common origin. The slightly concave downward shape proper to the east-west profile of Ahuna Mons, and proposed to be the result of viscous relaxation (Ruesch et al., 2016), is found for the east and south (S1) wall of Yamor Mons (Figs. 9 and 14). The generally lower flank steepness at Yamor Mons might be explained by the longer lasting impact cratering and mass wasting processes (Fig. 14). The topographic profile of Ahuna Mons is, however, due to the presence of a $\sim 7$ by $5 \mathrm{~km}$ large, relatively flat summit (Fig. 8). This feature is composed of a variety of morphologies (e.g., troughs and ridges, pits) that point to a volcanic origin (Ruesch et al., 2016). Yamor Mons clearly lacks a distinctive summit feature as well as associated morphologies. Whereas the lack of preserved morphologies can be explained by a period of longer-lasting impact gardening, the original topography and potential summit feature should not have been affected by this process. Additional information such as composition and gravity might be required to elucidate the origin of this dome.

Independently of the origin, Yamor Mons, and its northeast flank in particular, is an example of how domes on Ceres are eroded and possibly destroyed by impacts. Large impacts on a dome's slope do not only affect and move material during the excavation and relaxation phases of crater formation, but possibly trigger collapse of the entire upslope flank, well behind the final crater diameter.

\subsection{Shadowed areas}

Schorghofer et al. (2016) proposed that PSRs are cold traps with conditions favorable for the deposition of water ice from, for example, an exosphere. Thus, the brighter areas we identified are candidate deposits of ice, which is consistent with recent results presented in Platz et al. (2016). An alternative origin for the brighter material might be debris from the impact target, the same as the sloping floor material. However, the separation of target debris and concentration into two distinct deposits (darker sloping floor and brighter area) seems unlikely.

The fact that the pixels surrounding the possible impact craters are not as dark as the sloping floor (profile in Fig. 11E) indicates that the impact did not excavate the entire ice deposit down to the preexisting terrain. This suggests that a more recent (additional) deposition of ice occurred after the impact or that brighter material is as thick as the excavation depth, i.e., $20 \mathrm{~m}$ (e.g., Melosh, 1989).

Recent ice deposits may result from trapping of water molecules in cold PSRs. Exospheric water molecules travel on ballistic trajectories around the entire surface of Ceres, and seasonally reside at the winter pole where they might be preserved permanently in the cold traps (e.g., Schorghofer et al., 2016). Therefore recent deposition from the exosphere is expected to have occurred in all PSRs, and brighter areas should be more abundant than actually detected. As that is not the case, it appears more plausible that the brighter material is as thick as $20 \mathrm{~m}$. In addition, the accumulation rate from the exosphere is estimated at only $0.4 \mathrm{~m} / \mathrm{Ga}$, considering minimum supply rates (Schorghofer et al., 2016), and the fresh-appearing hosting craters are less than $1 \mathrm{Ga}$ old. The oldest crater preserving fresh-appearing morphologies (e.g., sharp rim crest at LAMO resolution, continuous ejecta blanket) for which an age could be derived is $\sim 250$ Ma old. These observations suggest that other sources, such as infall of exogenic material, should be considered as major contributors to the formation of the ice deposits. It is also unlikely that the brighter material represents exposed ground ice. During the impact process target material exposed on the floor of simple transient craters gets covered by subsequent mass wasting and is thus not visible in the final crater floors (e.g., Melosh, 1989). Excavated material might remain exposed in the upper walls in the form of spurs or on the ejecta, contexts different from those of the brighter material.

The most recent ice deposition (the one responsible for the formation of the area boundaries) has probably occurred before the latest downslope mass movements on the crater wall took place. This is indicated by the overlapping of brighter areas by darker streaks. Such downslope events possibly occurred during the most recent, Occator epoch, characterized by fresh appearing crater morphologies. A question remains on the nature of the brighter streak (Fig. 11D). The streak could be formed by ice moving downslope or be an apparent feature created by inhomogeneous coverage of underlying ice by darker material. Other features with origins sub- 
ject so speculation with the currently available data are the faint, darker lineaments on the ice deposits. The differences in shape and lengths between these lineaments and the darker streaks suggest that the origin is not associated with the presence of a darker material on top of the ice. Instead, the lineaments might represent troughs dissecting the brighter area. Troughs might form as a consequence of ice deposition on a topographically irregular surface, or after ice deposition, perhaps due to sublimation and collapse.

Overall, these interpretations derived from observations at the smallest possible, pixel-scale resolution confirm that candidate ice deposits exists in few locations in the north pole area of Ceres and were subject to recent modifications.

\subsection{Lobate materials}

Ghanan lobate material originates in a setting that produces the highest amount of material moving downslope. If the superposed impact had occurred closer to the Ghanan center, an asymmetric crater morphology would have resulted with less extensive mass wasting (Krohn et al., 2014), i.e., disruption of the Ghanan crater wall during the impact without subsequent collapse and downslope motion. If the impact had occurred farther away from the Ghanan rim crest, it is conceivable that a shorter section of the Ghanan wall would have collapsed. Instead, the scarps and slumped blocks on the southwest rim of the Ghanan superposed rim indicate that the lobate material consists mainly of the collapsed Ghanan wall. Ejecta from the superposed crater is probably a minor component to the lobate deposits.

Ghanan wall collapse was possibly triggered by the displacement of material at depth and structural uplifting at the rim during the impact excavation phase. Structural uplift occurs from the rim crest up to a distance of 1.3-1.7 crater radii (e.g., Melosh, 1989). The various ridges forming the southwest section of the superposed crater rim suggest that the wall collapsed in different sections, each one possibly providing the source region of discrete lobate material. An estimate of the velocity provided by the impact event to the displaced material can be obtained by considering the velocity of the ejecta close to the rim. For a 15-km large crater such speed is $26 \mathrm{~m} / \mathrm{s}$ (Melosh, 1989). "Covered" craters and lineaments across them suggest that the lobate material, once accelerated by the impact, advanced undisturbed by the underlying topographic obstacles. The large central ridge and trough are possibly also the result of preexisting relief and their overtopping suggests a high velocity flow (e.g., McEwen, 1989). The minimum velocity required to overtop a ridge of elevation $\mathrm{h} \sim 150 \mathrm{~m}$ can be estimated with $v=\left(2^{*} g^{*} h\right)^{0.5}$ (Eq. (1)) giving a value of $9 \mathrm{~m} / \mathrm{s}$ under Ceres' gravity g, consistent with the speed provided by the impact. Longitudinal grooves or lineaments have been interpreted to be the result of a high-speed landslide where the grooves form by differential shear of debris traveling at different speeds and lateral spreading (e.g., Lucchitta, 1979; McEwen, 1989). Although longitudinal grooves are known to form in a variety of contexts, they are reported to be more prominent in high-speed emplacements (Dufresne and Davies, 2009). Another estimate for the velocity of the lobate material can be obtained by considering a simple case of a sliding block on an inclined plane. A sliding block traveling for $25 \mathrm{~km}$ on an $11^{\circ}$ sloped plane requires an initial velocity of $75 \mathrm{~m} / \mathrm{s}$ for a friction coefficient of 0.6 (e.g., dry rock-on-rock friction) and $36 \mathrm{~m} / \mathrm{s}$ for a lower friction coefficient of 0.1 (lubricated materials). The comparison of these values with the velocity provided by the impact suggests that the lobate material was emplaced as a fast flow (few tens of meters per second) with possibly a low friction coefficient. These considerations use simplistic conditions that need to be supported by more detailed modeling of the effects of impacts on slopes and subsequent mass wasting processes. Nevertheless, they suggest that very slow movement such as ice-cored flows on Earth might not be a representative analog. Dry granular flows, instead, should not be excluded, as they appear to form impact-driven lobate material in a variety of surface conditions, e.g., Mercury and the Moon (Xiao and Komatsu, 2013; Boyce et al., 2016).

Buczkowski et al. (2016) identified lobate flows on Ceres and determined their global distribution. Here we compare the lobate flows distribution for latitudes $>66^{\circ}$ from Buczkowski et al. (2016) to the geologic map and lobate material definition (Section 4.1) of this study as well as with HAMO images. The latter need to be taken into account as the Buczkowski et al. (2016) results were performed without the images of the lowaltitude, LAMO phase of the mission, and hence were of lower spatial resolution than available in this study. In the quadrangle, Buczkowski et al. (2016) identify 10 lobate flows. Three of them are positively detected in HAMO images and HAMO DTM by the presence of steep marginal scarps, two of them correspond to lobate material in the geologic map of Fig. 2. The third lobate flow is recognized as degraded lobate material (Fig. 15A). Negative detections occur where terraces, slumped blocks, ejecta or hummocky areas are identified instead of lobes with steep marginal scarps. Fig. 15B and $C$ presents the case for detection of hummocky areas. The other morphologies are presented elsewhere in the study (see description of geologic units). Fig. 15B shows a negative detection where an apparent lobate material in FC image is identified. First, the material lacks steep sided margins in the HAMO DTM (Fig. 15D). Second, the apparent margins in the FC image are as wide as half of the lobe's entire width (Fig. 15C). Third, the lobate material is only apparent because its shape could be the result of a juxtaposed impact crater and the edges of the material could correspond to a section of a crater wall. In the negative detection of Fig. 15C, steep sided areas are identified but do not form a lobate shape, therefore lacking a diagnostic criterion of lobate material.

A global latitudinal distribution of lobate flow morphologies (Buczkowski et al., 2016; Schmidt et al., 2017) is not supported because the paucity of flows (three) recognized in the quadrangle is not statistically significant. We note that at latitudes $>30^{\circ} \mathrm{N}$, where the crater density is higher relative to the rest of Ceres' surface (Hiesinger et al., 2016), a concentration of lobate material is to be expected. Because lobate materials form as a consequence of crater superposition (i.e., impact-driven collapse of preexisting crater rim), their frequency is expected to be higher in a highly cratered area. Also, we note that the depth difference for ice stability modeled between the equator (few tens of $m$ depth) and the poles $(<0.5 \mathrm{~m})$ is minor (Schorghofer et al., 2016). Therefore, following this prediction, potential morphological differences between ice-free and ice-rich material should be evident only for morphologies controlled by the shallow subsurface. For example, between craters less than $500 \mathrm{~m}$ in diameter (impact in ice-free target) and craters larger than $\sim 1.5 \mathrm{~km}$ (mostly in potentially icerich target). Therefore, the lack of supporting evidence for a latitudinal control of lobate morphologies (at crater larger than $10 \mathrm{~km}$ ) is not surprising.

Buczkowski et al. (2016) recognized three different types of lobate materials on Ceres and draw similarities with fluidized ejecta blankets on Mars and Ganymede or ice-cemented low-speed flows on Earth. Key morphological differences between Ghanan lobate material ("steep frontal toes", "nested sets of parallel linear furrows" for type 1 flow in Buczkowski et al., 2016) and Jarovit lobate material ("long, fan-shaped", "composed of platy sheets with rounded tapered toes" for type 2 flow, Buczkowski et al., 2016) are not recognized in this study. Minor differences can be ascribed to the different locations of the superposed craters on the preexisting rims and to age differences (i.e., Jarovit flow surface is more degraded and cratered). Instead, the ubiquitous association of lobate material to impact superposition (i.e., impact on a 

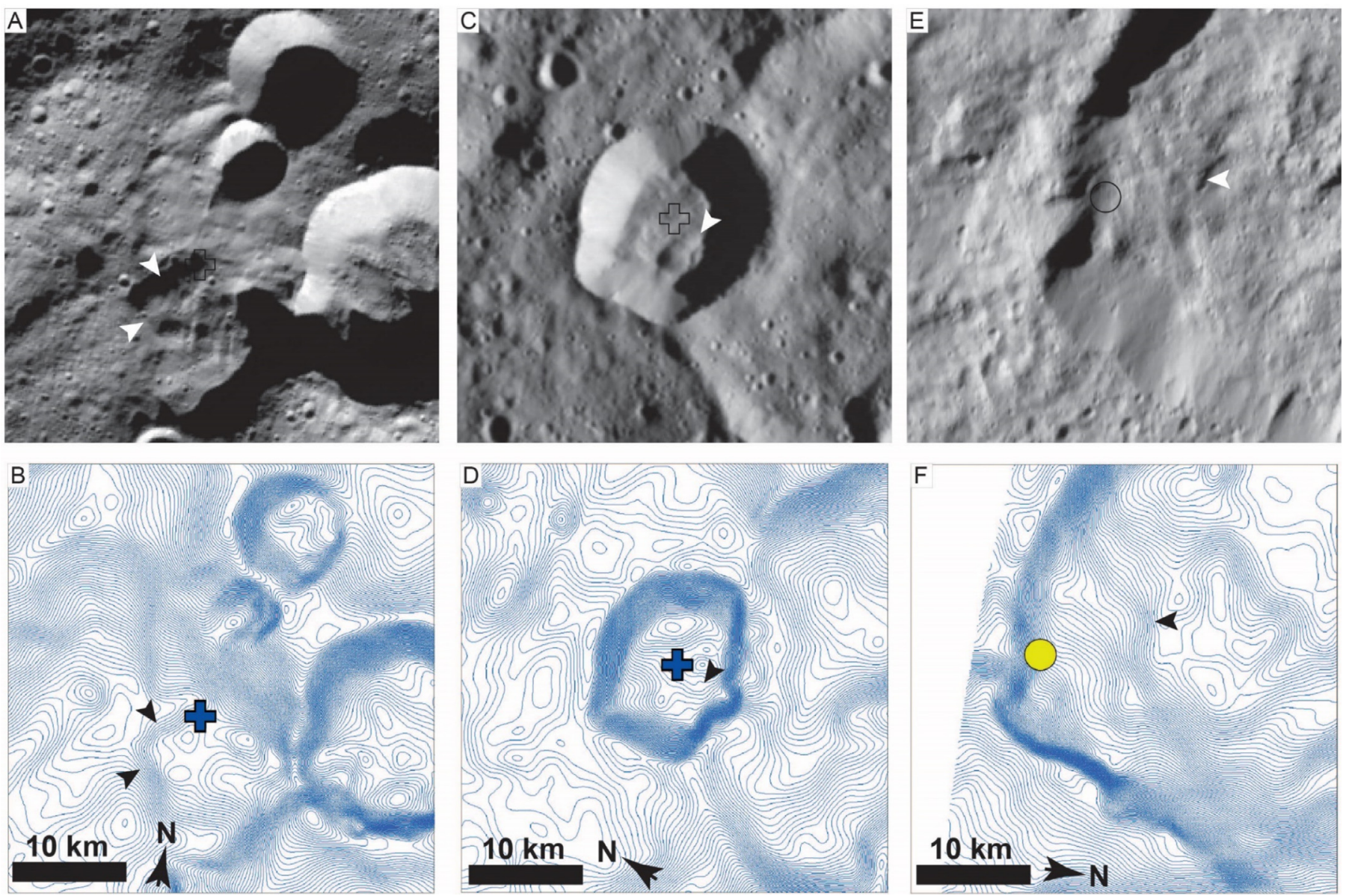

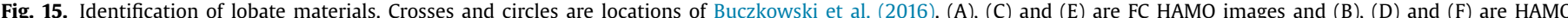

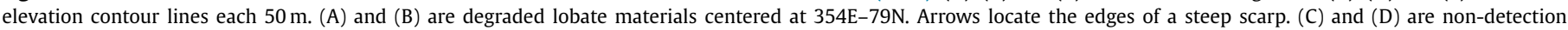

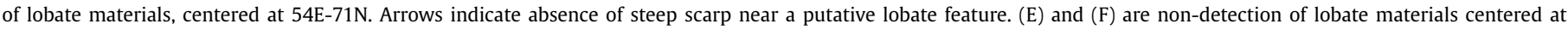
$260 \mathrm{E}-66 \mathrm{~N}$. Arrows point to a steep scarp without a lobate shape in plan view.

preexisting crater rim) in the quadrangle area suggests an origin as high-speed debris flow due to impact-driven rim collapse.

\section{Conclusion}

The geology of Ceres' North Pole quadrangle $\left(90^{\circ} \mathrm{N}-66^{\circ} \mathrm{N}\right)$ preserves an ancient, highly cratered terrain. The formation or modification of this terrain by cryovolcanism, a possibility suggested by $4.5 \mathrm{~km}$ high Yamor Mons, remains an open question as the pristine morphological features of the potential dome have been erased by impact cratering. Several impact craters up to $\sim 30 \mathrm{~km}$ in diameter and associated lobate materials possibly formed in the recent Occator epoch (characterized by fresh appearing crater morphologies.). Their pristine morphology and morphometry, as detailed in this work, reveal the following:

- Lobate materials in the north polar area of Ceres can originate during impacts on a preexisting crater rim, possibly as highspeed flow (few tens of meters per second).

- Images at the highest available spatial resolution demonstrate a paucity of lobate materials, in contrast to the identifications with lower spatial resolution data. The paucity of lobate materials at latitudes $>66^{\circ} \mathrm{N}$ indicates no latitudinal control on abundance of lobate material, which is instead a function of crater density.

- Permanently Shadowed Regions (PSRs) on crater interiors host bright deposits interpreted as potential ice accumulations. The rarity of the deposits relative to the abundant PSRs and the deposit thicknesses suggest a possibly important role of exogenic material infall. Pixel-scale, photo-geologic analyses of FC LAMO images reveal that the deposits were affected by downslope mass movement during the recent Occator epoch.

- A comparison between measurements of crater size-frequency distribution and asteroid-derived and lunar-derived models of crater production (ADM and LDM) reveals discrepancies, similar to differences found for the cratering record on the asteroid Vesta.

\section{Acknowledgment}

We acknowledge the throughout review of a previous version of this manuscript by three anonymous referees. O.R. is supported by an appointment to the NASA Postdoctoral Program at the NASA Goddard Space Flight Center administered by Universities Space Research Association through a contract with NASA. The Framing Camera system on the spacecraft was developed and built under the leadership of the Max Planck Institute for Solar System Research in Göttingen, Germany, in collaboration with the DLR Institute of Planetary Research in Berlin and the Institute of Computer and Communication Network Engineering in Braunschweig. The Framing Camera project is funded by the Max Planck Society, DLR, and NASA/JPL. Dawn Framing Camera data are archived with the NASA Planetary Data System (http://sbn.psi.edu/pds/resource/ dwncfc2.html). 


\section{References}

Bland, M.T., Raymond, C.A., Schenk, P.M., Fu, R.R., Kneissl, T., Pasckert, J.H., Hiesinger, H., et al., 2016. Composition and structure of the shallow subsurface of Ceres as revealed by crater morphology. Nat. Geosci. 9, 538-542. doi:10.1038/ NGO2743.

Boyce, J., Barlow, N., Mouginis-Mark, P., Stewart, S., 2010. Rampart craters on Ganymede: their implications for fluidized ejecta emplacement. Met. Planet. Sci. $45,638-661$.

Boyce, J.M., Mouginis-Mark, P., Robinson, M., 2016. An LROC update: the Tsiolkovsky landslide. 47th Lunar and Planetary Science Conference Abstract 2471.

Bray, V.J., Tornabene, L.L., Keszthleyi, L.P., McEwen, A.S., Hawke, B.R., Giguere, T.A., Kattenhorn, S.A., et al., 2010. New insight into lunar impact melt mobility from the LRO camera. Geophys. Res. Lett. 37, 21.

Buczkowski, D., Schmidt, B.E., Williams, D.A., Mest, S.C., Scully, J.E.C., Ermakov, A.I., Preusker, F., et al., 2016. The geomorphology of Ceres. Science 353 (6306). doi:10.1126/science.aaf4332.

Carr, M.H., Crumpler, L.S., Cutts, J.A., Greeley, R., Guest, J.E., Masursky, H., 1977. Martian impact craters and emplacement of ejecta by surface flow. J. Geophys. Res. $82,4055-4065$

Denevi, B.W., Koeber, S.D., Robinson, M.S., Garry, W.B., Hawke, B.R., Tran, T.N., Lawrence, S.J., 2012. Physical constraints on impact melt properties from Lunar Reconnaissance Orbiter Camera images. Icarus 219 (2), 665-675.

Dufresne, A., Davies, T.R., 2009. Longitudinal ridges in mass movement deposits. Geomorphology 105, 171-181.

Hayne, P.O., Aharonson, O., 2015. Thermal stability of ice on Ceres with rough topography. J. Geophys. Res. 120, E004887.

Hiesinger, H., Marchi, S., Schmedemann, N., Schenk, P., Pasckert, J.H., Neesemann, A., O'Brien, D.P., et al., 2016. Cratering on Ceres: implications for its crust and evolution. Science 353 (6306). doi:10.1126/science.aaf4759.

Ivanov, B.A., 2001. Mars/Moon cratering rate ratio estimates. Space Sci. Rev. 96, 87-104.

Jaumann, R., Williams, D.A., Buczkowski, D.L., Yingst, R.A., Preusker, F., Hiesinger, H., Schmedemann, N., et al., 2012. Vesta's shape and morphology. Science 336, 336-687.

Kneissl, T., van Gasselt, S., Neukum, G., 2011. Map-projection-independent crater size-frequency determination in GIS environments - new software tool for ArcGIS. Planet. Space Sci. 59, 1243-1254.

Kneissl, T., Schmedemann, N., Reddy, V., Williams, D.A., Walter, S.H.G., Neesemann, A., Michael, G.G. et al., 2014. Morphology and formation ages of midsized post-Rheasilvia craters - Geology of quadrangle Tuccia, Vesta. Icarus 244, 133-157.

Krohn, K., Jaumann, R., Elbeshausen, D., Kneissl, T., Schmdemann, N., Wagner, R., Voigt, J., et al., 2014. Mass movement on Vesta at steep scarps and crater rims. Icarus 244, 120-132.

Krohn, K., Jaumann, R., Stephan, K., Otto, K.A., Schmedemann, N., Wagner, R.J., Matz, K.-D., Tosi, F., Zambon, F., et al., 2016. Cryogenic flow features on Ceres: implications for crater-related cryovolcanism. Geophys. Res. Lett. doi:10.1002/ 2016GL070370.

Krueger, T., van der Bogert, C.H., Hiesinger, H., 2016. Geomorphologic mapping of the lunar crater Tycho and its impact melt deposits. Icarus 273, 164-181.

Lucchitta, B.K., 1979. Landslides in Valles Marineris, Mars. J. Geophys. Res. 84 (B14), $8097-8113$.

Marchi, S., Ermakov, A.I., Raymond, C.A., Fu, R.R., O’Brien, D.P., Bland, M.T., Ammannito, E., et al., 2016. The missing large impact craters on Ceres. Nat. Commun. 7. doi:10.1038/ncomms12257.

McEwen, A.S., 1989. Mobility of large rock avalanches: evidence from Valles Marineris, Mars. Geology 17, 1111-1114.

Melosh, H.J., 1989. Impact cratering a geological process. Oxford Monographs on Geology and Geophysics No. 11. Oxford University Press (ISBN 0-19-504284-0).

Nathues, A., Hoffmann, M., Schaefer, M., Le Corre, L., Reddy, V., Platz, T., Cloutis, E.A., 2015. Sublimation in bright spots on (1) Ceres. Nature 528, 237-240.
Neish, C.D., Madden, J., Carter, L.M., Hawke, B.R., Giguere, T., Bray, V.J., Osinski, G.R., Cahill, J.T.S., 2014. Global distribution of lunar impact melt flows. Icarus 239, 105-117.

O'Brien, D.P., Marchi, S., Morbidelli, A., Bottke, W.F., Schenk, P.M., Russell, C.T., Raymond, C.A., 2014. Constraining the cratering chronology of Vesta. Planet. Space Sci. 103, 131-142.

Platz, T., Nathues, A., Schorghofer, N., Preusker, F., Mazarico, E., Schroeder, S.E., Byrne, S., et al., 2016. Surface water-ice deposits in the northern shadowed regions of Ceres. Nat. Astron. 1, 007.

Plescia, J.B., Cintala, M.J., 2012. Impact melt in small lunar highland craters. J. Geophys. Res. 117 (E12).

Preusker, F., Oberst, J., Head, J.W., Watters, T.R., Robinson, M.S., Zuber, M.T., Solomon, S.C., 2011. Stereo topographic models of Mercury after three MESSENGER flybys. Planet. Space Sci. 59, 1910-1917. doi:10.1016/j.pss.2011.07.005.

Preusker, F., Scholten, F., Matz, K.-D., Roatsch, T., Willner, K., Hviid, S.F., Knollenberg, J., et al., 2015. Shape model, reference system definition, and cartographic mapping standards for comet 67P/Churyumov-Gerasimenko - stereo-photogrammetric analysis of Rosetta/OSIRIS image data. Astron. Astrophys 583, A33.

Roatsch, T., Kersten, E., Matz, K.-D., Preusker, F., Scholten, F., Jaumann, R., Raymond, C.A., Russell, C.T., 2016. High-resolution Ceres High Altitude Mapping Orbit atlas derived from Dawn Framing Camera images. Planet. Space Sci. 129, 103-107.

Ruesch, O., Hiesinger, H., Blewett, D.T., Williams, D.A., Buczkowski, D., Scully, J. Yingst, R.A., et al., 2014. Geologic map of the northern hemisphere of Vesta based on Dawn Framing Camera (FC) images. Icarus 244, 41-59.

Ruesch, O., Platz, T., Schenk, P., McFadden, L.A., Castillo-Rogez, J.C., Quick, L.C., Byrne, S., et al., 2016. Cryovolcanism on Ceres. Science 353 (6306). doi:10.1126 science.aaf4286.

Russell, C.T., Raymond, C.A., Ammannito, E., Buczkowski, D.L., De Sanctis, M.C, Hiesinger, H., Jaumann, R., et al., 2016. Dawn arrives at Ceres: exploration of a small, volatile-rich world. Science 353 (6303), 1008-1010.

Schmidt, B.E., Hughson, K.G., Chilton, H.T., Scully, J.E.C., Platz, T., Nathues, A., Sizemore, H., et al., 2017. Geomorphological evidence for ground ice on dwarf planet Ceres. Nat. Geosci. 10 (5), 338-343.

Schmedemann, N., Kneissl, N., Ivanov, B.A., Michael, G.G., Wagner, R.J., Neukum, G., Ruesch, O., et al., 2014. The cratering record, chronology and surface ages of (4) Vesta in comparison to smaller asteroids and the ages of the HED meteorites. Planet. Space Sci 103, 104-130.

Schroeder, S.E., Mottola, S., Matz, K.-D., Roatsch, T., 2014. In-flight calibration of the Dawn Framing Camera II: Flat fields and stray light correction. Icarus 234, 99108. doi:10.1016/j.icarus.2014.02.018.

Schorghofer, N., Mazarico, E., Platz, T., Preusker, F., Schroeder, S.E., Raymond, C.A., Russell, C.T., 2016. The permanently shadowed regions of dwarf planet Ceres. Geo. Res. Let. 43 (13), 6783-6789.

Senft, L.E., Stewart, S.T., 2008. Impact crater formation into icy layered terrains on Mars. Met. Planet. Sci 43, 1993-2013.

Sierks, H., Keller, H.U., Jaumann, R., Michalik, H., Behnke, T., Bubenhagen, F., Buettner, I., et al., 2011. The Dawn Framing Camera. Space Sci. Rev. 163, 263-327.

Tanaka, K.L., Skinner Jr., J.A., Crumpler, L.S., Dohm, J.M., 2009. Assessment of planetary geologic mapping techniques for Mars using terrestrial analogs: the SP Mountain area of the San Francisco Volcanic Field, Arizona. Planet. Space Sci. 57 (5-6), 510-532. doi:10.1016/j.pss.2008.06.012.

Wilhelms, D.E., McCauley, J.F., Trask, N.J., The geologic history of the Moon. USGS Prof. Pap., 1348, p. 302, (1987).

Williams, D.A., O’Brien, D.P., Schenk, P.M., Denevi, B.W., Carsenty, U., Marchi, S., Scully, J.E.C., 2014. Lobate and flow-like features on asteroid Vesta. Planet. Space Sci. 103, 24-35.

Williams, D.A., Buczkowski, D.L., Mest, S.C.P., Scully, J.E.C., 2017. Introduction: the geologic mapping of ceres. Icarus doi:10.1016/j.icarus.2017.05.004.

Xiao, Z., Komatsu, G., 2013. Impact craters with ejecta flows and central pits on Mercury. Planet. Space Sci. 82-83, 62-78. 